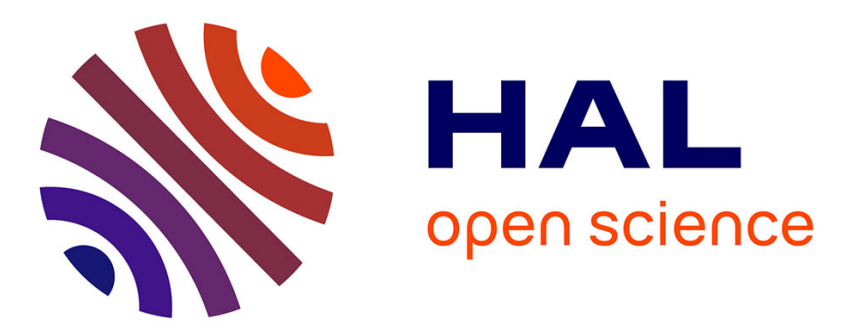

\title{
About electrical resistivity variation during drying and improvement of the sensing behavior of carbon fiber-reinforced smart concrete
}

Hamza Allam, François Duplan, Jean-Pierre Clerc, Sofiane Amziane, Yves Burtschell

\section{To cite this version:}

Hamza Allam, François Duplan, Jean-Pierre Clerc, Sofiane Amziane, Yves Burtschell. About electrical resistivity variation during drying and improvement of the sensing behavior of carbon fiber-reinforced smart concrete. Construction and Building Materials, 2020, 264, pp.1-11. 10.1016/j.conbuildmat.2020.120699 . hal-03086122

\section{HAL Id: hal-03086122 \\ https://hal.uca.fr/hal-03086122}

Submitted on 4 Jan 2021

HAL is a multi-disciplinary open access archive for the deposit and dissemination of scientific research documents, whether they are published or not. The documents may come from teaching and research institutions in France or abroad, or from public or private research centers.
L'archive ouverte pluridisciplinaire HAL, est destinée au dépôt et à la diffusion de documents scientifiques de niveau recherche, publiés ou non, émanant des établissements d'enseignement et de recherche français ou étrangers, des laboratoires publics ou privés. 


\section{About electrical resistivity variation}

\section{during drying and improvement of the}

sensing behavior of carbon fiber-

\section{reinforced smart concrete}

Hamza Allam', François Duplan'1, Jean-Pierre Clerc', Sofiane Amziane², Yves Burtschell11

${ }^{1}$ Aix-Marseille Université, CNRS, IUSTI UMR 7343, 13453, Marseille, France

2 Univ. Clermont Auvergne, CNRS, Sigma, Institut Pascal, UMR 6602, Clermont-Ferrand, France

HIGHLIGHTS

- The electrical impedance of fiber-reinforced and non-fiber-reinforced mortar varies with drying.

- Variation of impedance depends on presence and volume fraction of carbon fibers.

- Water loss during drying increases impedance for non-fibrous mortar.

- In the presence of fibers, impedance tends towards a resistive behavior over drying time. 


\title{
- Coupling fibers with a specific monitoring frequency limits sensing uncertainty caused by drying.
}

\begin{abstract}
The addition of conductive fibers to a cementitious material reduces its electrical impedance, for monitoring purposes, based on the relationship between external stresses (mechanical or thermal) and changes in electrical properties. In this context, variations in the electrical properties due to drying prevent the application of this technique, unless such variations are negligible or precisely predictable. The aim of this paper, therefore, is to study the variation of the complex electrical impedance during drying, for measurement frequencies between $4 \mathrm{~Hz}$ and $1 \mathrm{MHz}$. Shrinkage, weight loss and electrical impedance spectrum were measured on three mortars with carbon fiber volume fractions (FVF) of $0,0.1$ and $0.5 \%$. The results show that in the absence of conductive fibers, the real and imaginary parts of the impedance increase due to water loss. On the other hand, in the presence of a percolated carbon fiber network, the real impedance of the material decreases at low frequencies and increases at high frequencies during drying; for intermediate frequency ranges, quasi-constant values can be observed. In addition, as the material dries, the capacitive behavior of the material wanes, and the imaginary impedance values tend towards 0 . The electrical behavior then approaches ideal resistive behavior with a real impedance value independent of the measurement frequency. Blind frequencies have been identified for fibrous mortars around $1 \mathrm{kHz}$ and $40 \mathrm{kHz}$ for $0.1 \%$ and $0.5 \% \mathrm{FVF}$, respectively. For monitoring purposes, coupling the presence of fibers with an appropriate measurement frequency would minimize the effects related to the variation of impedance as a function of time - i.e., allowing more precise monitoring of mechanical loads with time.
\end{abstract}


Keywords: Mortar, carbon fibers, electrical impedance, drying, shrinkage, smart concrete, sensing

\section{INTRODUCTION}

"Smart concrete" is composed of an ordinary cementitious matrix (cement paste, mortar, concrete...) with the inclusion of conductive fillers which may be of different aspect ratios [1][2], different forms (particles [3], nanotubes [4][5], or fibers [6][7][8]) and different materials (carbon [7], steel [9], Conductive rubber fibers [10]...). The addition of conductive fillers decreases the electrical resistivity of the material and induces a quasi-linear relationship between that resistivity and the deformation of the material (i.e., it develops piezoresistive behavior). Since electrical fractional variation is induced by deformation, it is possible to measure the electrical resistance or impedance of a volume of the material in order to estimate the mechanical deformation under compression [9][11][12][13][14], tension [11][15], damage [16][17][18] and temperature variation [19][20]. Smart concrete could also serve other potential applications like pavement heating [21] or electromagnetic shielding [22] and monitoring the setting and hardening behavior of cement paste [23].

Initially, the cementitious matrix structure is saturated with water. A fraction of this water is consumed by the hydration reactions of the cement, while the excess water remains within the cement paste, filling the capillary pores. If the curing conditions are "wet", samples are immersed in water, keeping the surrounding environment at $100 \%$ relative humidity. In dry curing conditions, the relative humidity of the surrounding environment is lower than that of the internal structure of the material and the water consumed by the hydration of the cement is not replaced. Thus, the water in the interstitial solution retained in the capillary pores of the cement paste is liable to evaporate. This causes a decrease in the capillary pressure applied to the pore walls [24] and a decrease in the surface tension [25], which results in a volume contraction of the 
material, that is referred to as drying shrinkage [26]. These drying phenomena create water gradients between the core and perimeter of the sample on a macroscopic scale, as well as deformation gradients between the aggregates and cement paste. Curing conditions and material composition play a major role in the progress of drying shrinkage.

The effect of cementitious matrix drying on its electrical resistivity was analyzed and quantified

on several occasions. In the absence of conductive additions, the electrical resistivity of a cementitious material relates mainly to its ability to transport charges ionically through the liquid phase [27]. For porous water-impregnated rocks, Archie [28] identified a power law describing the dependence of the resistivity on the degree of saturation of the pores and connectivity of the liquid phase inside the pores. This empirical relation was subsequently explained [29] by applying percolation theory. The conductivity of cementitious materials [30] was presented as the multiplication of three factors depending on: conductivity of pore fluid, volume of capillary water and connectivity of this liquid phase. With drying, the ionic concentration of the pore solution may increase [30], decreasing the intrinsic resistivity of the liquid. However, water evaporation decreases the degree of saturation of the capillary porosity in the liquid phase, thus predominantly limiting the ionic transport of electric charges [31]. Moreover, it has been observed that as the hydration of cement progresses, it leads to a decrease in the volume fraction of capillary pores and their connectivity, and consequently an increase in resistivity. Resistivity has also been shown to depend on initial water content [32], where a higher initial liquid volume increases the conductivity of cementitious materials. Other studies have defined a critical threshold for the percolation of water into the pore network, beyond which the percolation of the liquid network of capillary pores is no longer guaranteed, causing an increase in resistivity [33]. This strong dependence of the electrical resistivity of cementitious materials on their degree of 
saturation, and thus on their water content, is applied to non-destructively evaluate the water content [34].

Conductive additions significantly decrease the electrical resistivity of materials, especially when they create a percolated network [35]. The volume fraction [36], shape [1] and degree of dispersion of the fibers [37] are major factors in the percolation of the fibers. The understanding of he resistivity variation with time after mixing is crucial to ensure a reliable piezoresistive behavior for fibrous mortar defined as self-sensing material, since drying (that includes water loss and length shrinkage) would affect electrical properties of fibrous mortar, and would therefore, cause secondary effects on resistivity variation if not uncoupled from external mechanical loads The effect of drying on impedance variation, studied previously, depends on drying conditions, fillers nature and volume fraction. With carbon fiber additions, under wet curing conditions, the ncrease in hydration degree leads to an increase in electrical resistivity [38]. With DC neasurements, in presence of a small amount of multi-walled nano tubes, drying caused an crease in resistivity [5]. When the volume fraction of the composite filler was high enough to ensure percolation (carbon nanotube/nanocarbon black [40], carbon black [41]), DC resistivity of fibred matrix was proved to diminish with time due to fiber presence. Under dry curing conditions, using AC impedance measurements to assess electrical properties, the presence of a percolated carbon fiber network was proved to greatly limits the increase in AC ultimate electrical esistivity during drying [39]

The objective of this paper is to quantify the drying effect on fibrous mortar depending on fibe olume fraction and use this understanding to minimize the drying secondary effect on selfensing of the self-sensing fibrous mortar. For this purpose, AC measurements are adopted since hey present the advantage of polarization reduction. AC impedance measurements are provided on a wide range of frequencies between $4 \mathrm{~Hz}$ and $1 \mathrm{MHz}$ in order to cover the variation of 
impedance function of measurement frequency and show, if any, a differential drying effec

depending on measurement frequency. Shrinkage, weight loss and electrical impedance spectrum

will be measured on three mortars covering three different fiber percolation stages: reference

mortar (0 \% fibers), low-fiber mortar (0.1\% fiber volume fraction) and high-fiber mortar $(0.5 \%$

fiber volume fraction). After determining the impedance variation over drying period, drying

effect would be uncoupled from self-sensing application by adopting specific monitoring

requencies to enhance sensibility's precision

\section{MATERIALS AND METHODS}

\subsection{Material}

The carbon fibers used are produced by Toho Tenax; they are $6 \mathrm{~mm}$ in length and $7 \mu \mathrm{m}$ in diameter. Their surface has not been subjected to any polymer impregnation treatment. The cementitious matrix is made with CALCIA CEMI $52.5 \mathrm{R}$ cement, standard sand conforming to EN 196-1 [42], respecting the grain size distribution presented in Table 1, and polycarboxylate-based superplasticizer BASF MasterGlenium ACE 550, the volume of which is increased proportionally to fiber volume fraction to ensure acceptable workability, not exceeding $4 \%$ of cement weight to avoid bleeding. The three mortars tested have the same $\mathrm{W} / \mathrm{C}$ ratio $(0.4)$ and the same sand volume fraction $40 \%$ (i.e. a sand-to-cement ratio of 1.27). The mix proportions are summarized in Table 2.

Table 1: Sand grain size distribution

\begin{tabular}{|l|l|}
\hline Diameter $\mathbf{( m m )}$ & Passing $\mathbf{( \% )}$ \\
\hline 0.063 & 0.03 \\
\hline 0.125 & 2.41 \\
\hline 0.25 & 24.86 \\
\hline 0.5 & 34.19 \\
\hline 1 & 68.81 \\
\hline 1.6 & 100 \\
\hline
\end{tabular}




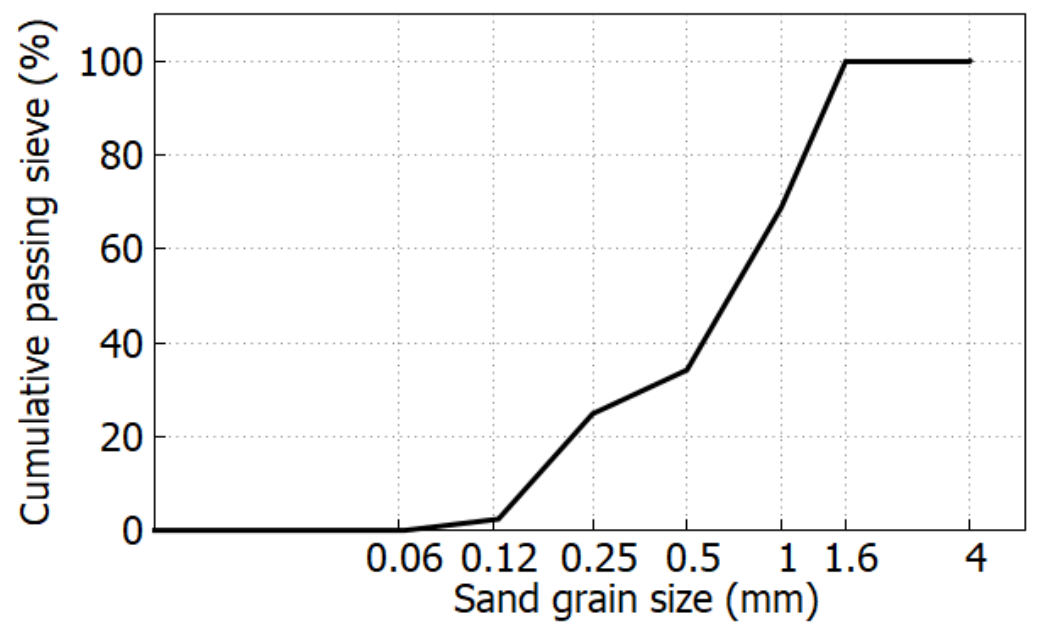

Fig. 1: Sand grain size distribution

Table 2: Mix proportions of the mortar

\begin{tabular}{|c|c|c|c|c|c|c|c|}
\cline { 2 - 8 } \multicolumn{1}{c|}{} & $\begin{array}{c}\text { Cement } \\
\text { ratio } \\
\text { (g/l) }\end{array}$ & $\begin{array}{c}\text { Sand- } \\
\text { to- } \\
\text { cement } \\
\text { ratio }\end{array}$ & $\begin{array}{c}\text { Water- } \\
\text { to- } \\
\text { cement } \\
\text { ratio }\end{array}$ & $\begin{array}{c}\text { Superplasticizer } \\
\text { Weight (ratio- } \\
\text { to-cement- } \\
\text { weight) }\end{array}$ & $\begin{array}{c}\text { Carbon } \\
\text { fibers } \\
\text { weight } \\
\text { (volume } \\
\text { fraction) }\end{array}$ & $\begin{array}{c}\text { Flexural } \\
\text { strength } \\
\text { (MPa) }\end{array}$ & $\begin{array}{c}\text { Compressive } \\
\text { strength } \\
\text { (MPa) }\end{array}$ \\
\hline $\begin{array}{c}\text { Reference } \\
\text { mortar }\end{array}$ & 830 & 1.27 & 0.4 & $0 \mathrm{~g}(0 \%)$ & $0 \mathrm{~g}(0 \%)$ & 11.08 & 79.37 \\
\hline $\begin{array}{c}\text { Low- } \\
\text { fiber } \\
\text { mortar }\end{array}$ & 830 & 1.27 & 0.4 & $6 \mathrm{~g}(0.72 \%)$ & $\begin{array}{c}1.8 \mathrm{~g}(0.1 \\
\%)\end{array}$ & 11.8 & 80.79 \\
\hline $\begin{array}{c}\text { High- } \\
\text { fiber } \\
\text { mortar }\end{array}$ & 830 & 1.27 & 0.4 & $15 \mathrm{~g}(1.81 \%)$ & $\begin{array}{c}9 \mathrm{~g}(0.5 \\
\%)\end{array}$ & 12.58 & 77.3 \\
\hline
\end{tabular}

The mortars are mixed in a Perrier mixer, at a constant low rotation speed of $140 \mathrm{rpm}$, according to the following sequence: 1 min with cement, sand, and fibers, then 2 minutes after adding water and superplasticizer. The three samples measuring $4 * 4^{*} 16 \mathrm{~cm}$ were unmolded at 24 hours, then 
immersed at $20^{\circ} \mathrm{C}$ for 28 days of wet curing. The samples are then placed in a controlled environment at $20^{\circ} \mathrm{C}$ and $50 \% \mathrm{RH}$ for 344 days.

\subsection{Experimental setup}

To monitor the deformation induced by drying shrinkage, the length and weight variation of the $4^{*} 4^{*} 16 \mathrm{~cm}$ samples and weight variation are tracked over 344 days of drying. The AC impedance of samples was measured between $4 \mathrm{~Hz}$ and $1 \mathrm{MHz}$, where the measurements were recorded at 33 frequencies points per decade within this frequency range, 179 frequencies over the frequency range), using a Hioki IM3750 impedance analyzer with a voltage of $0.1 \mathrm{~V}$. The electrodes are copper plates, affixed to the $4^{*} 4^{*} 16 \mathrm{~cm}$ samples by means of conductive adhesive copper foil installed on conductive nickel paint applied to the ends of the dried samples after careful polishing [35]. A two-electrode configuration is adopted.

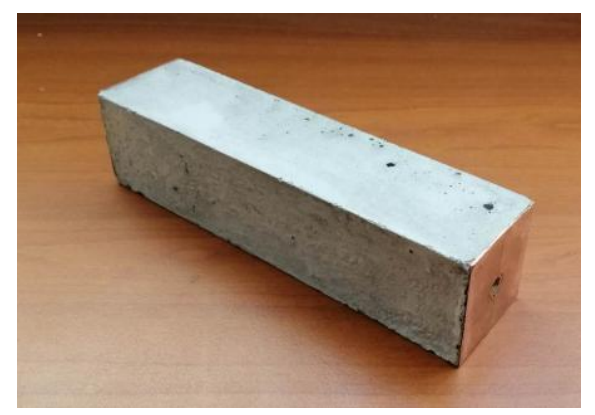

(a)

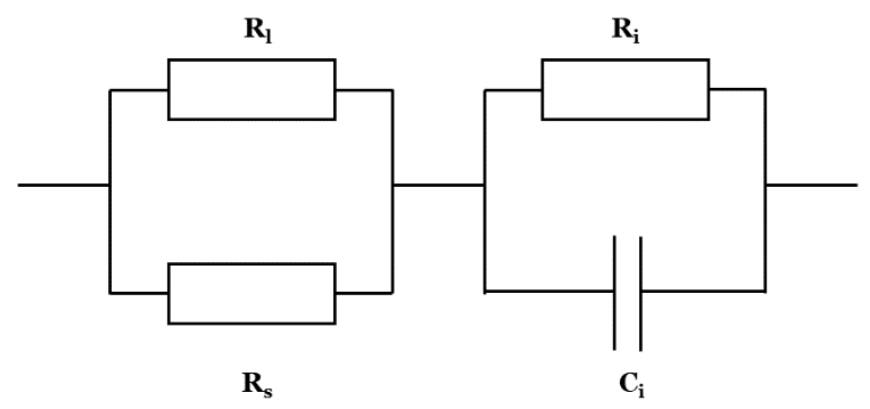

(b) 


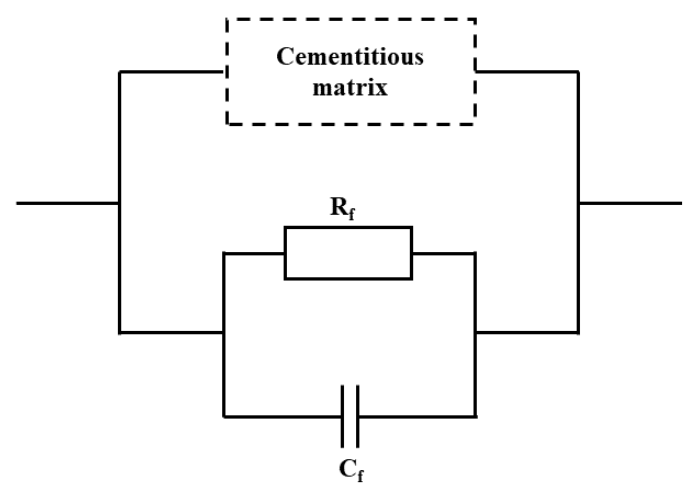

(c)

Fig 16: (a) Mortar specimen after hydration and fixation of copper foils (b) Non-fibrous mortar equivalent circuit ( $R_{1}$ is the liquid resistance, $R_{s}$ is the solid resistance, $R_{i}$ and $C_{i}$ are the interface resistance and capacitance respectively) (c) Fibrous mortar equivalent circuit $\left(R_{\mathrm{f}}\right.$ and $\mathrm{C}_{\mathrm{f}}$ are resistance and capacitance of fibers network)
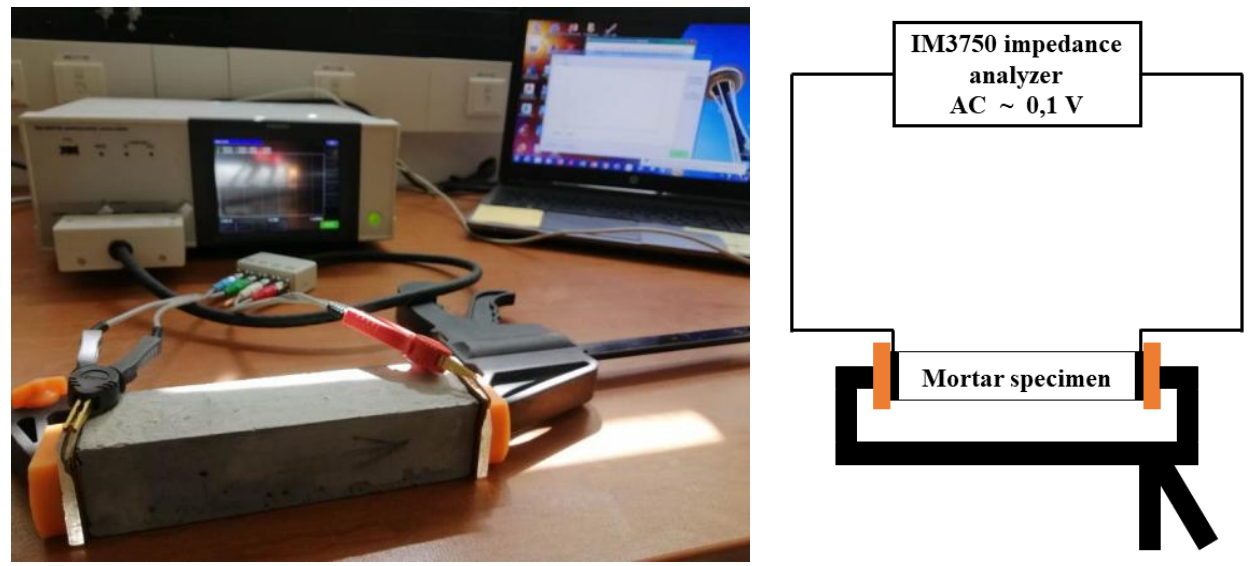

Fig. 2: Measurement setup

It is important to note that recording began at the end of the 28 days wet curing - i.e. no significant effect of hydration shrinkage was observed, and the dominant factor is the drying shrinkage. The impedance values (real and imaginary) illustrated in the results section are the mean measured impedance values for the 3 samples of every formulation.

After 344 days of drying, the sensitivity of the mortar to external loads was tested by subjecting samples to compression cycles between $0.6 \mathrm{MPa}$ and $5 \mathrm{MPa}$ with compression and decompression 
velocities of $+0.1 \mathrm{MPa} / \mathrm{s}$ and $-0.1 \mathrm{MPa} / \mathrm{s}$ respectively and behavior stabilization thresholds of $10 \mathrm{~s}$, in parallel to AC real impedance measurement every $1 \mathrm{~s}$ at a voltage of $0.1 \mathrm{~V}$.
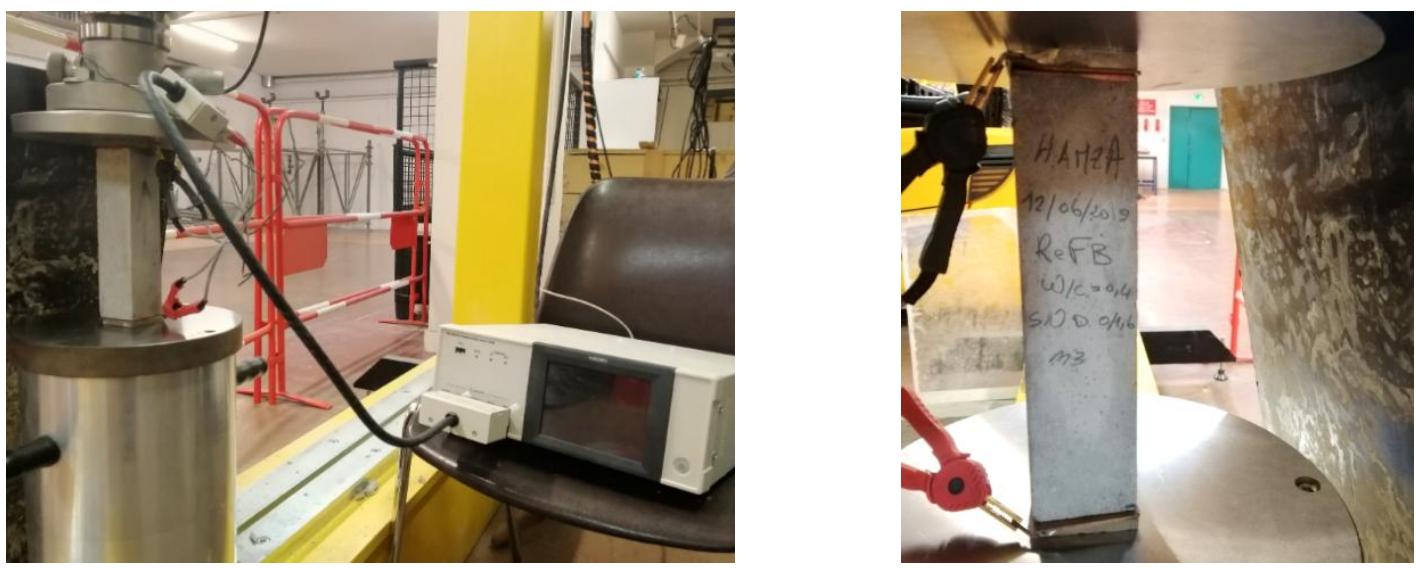

Fig. 3: Compression test setup

\subsection{Impedance dispersion assessment over time}

For every formulation, three specimens were tested, as stated previously. For every sample, in order to quantify the variation over time of real impedance values at a given frequency, the following statistical parameters were calculated:

$$
\begin{gathered}
\bar{X}=\frac{1}{n} \sum x_{i} \\
\sigma=\frac{1}{n} \Sigma\left(x_{i}-\bar{X}\right)^{2} \\
c_{v}=\sigma / \bar{X}
\end{gathered}
$$

Where $\bar{X}$ is the mean of real impedance measured at a given frequency $\mathrm{f}_{\mathrm{i}}$ over time, $\mathrm{n}$ is the number of measurements over time (66 in this study over the 344 days), $x_{i}$ is the real impedance value at a given date, $\sigma$ is the standard deviation characterizing the dispersion of real impedance at a given frequency $f_{i}$ over time, and $c_{v}$ is the relative standard deviation. Using these properties, it is possible to detect which frequencies, if any, are less affected by drying. Monitoring the sensing behavior at such frequencies could make it more stable, being less closely coupled with the internal effects related to water loss and shrinkage. 


\section{RESULTS}

\subsection{Weight loss and shrinkage}

Fig. 4 and 5 show the variation in weight loss and shrinkage of mortar samples after 28 days of wet curing. The weight loss and shrinkage curves show conventional asymptotic trends. They are almost identical for the reference mortar and the mortar with a fiber volume fraction of $0.1 \%$. On the other hand, the mortar with a fiber volume fraction of $0.5 \%$ shows higher values of mass loss (13\% higher at the end of the study) and shrinkage (26\% higher at the end of the study).

Fig. 6 also shows that the relationship between shrinkage and weight loss is slightly impacted by the presence of fibers. Here, in the absence of significant changes in the degree of hydration of the cement, the fibers magnify the drying shrinkage of the mortar at equivalent weight loss values. The relationship between shrinkage and mass loss is almost linear in an initial phase up to $2.5 \%$ weight loss (for non-fibrous mortar and low-fiber mortar) and $3 \%$ (for high-fiber mortar); both thresholds correspond to a drying time equal to 120 days. Then, in the second phase, the weight loss continues to evolve while the shrinkage tends towards a constant value.

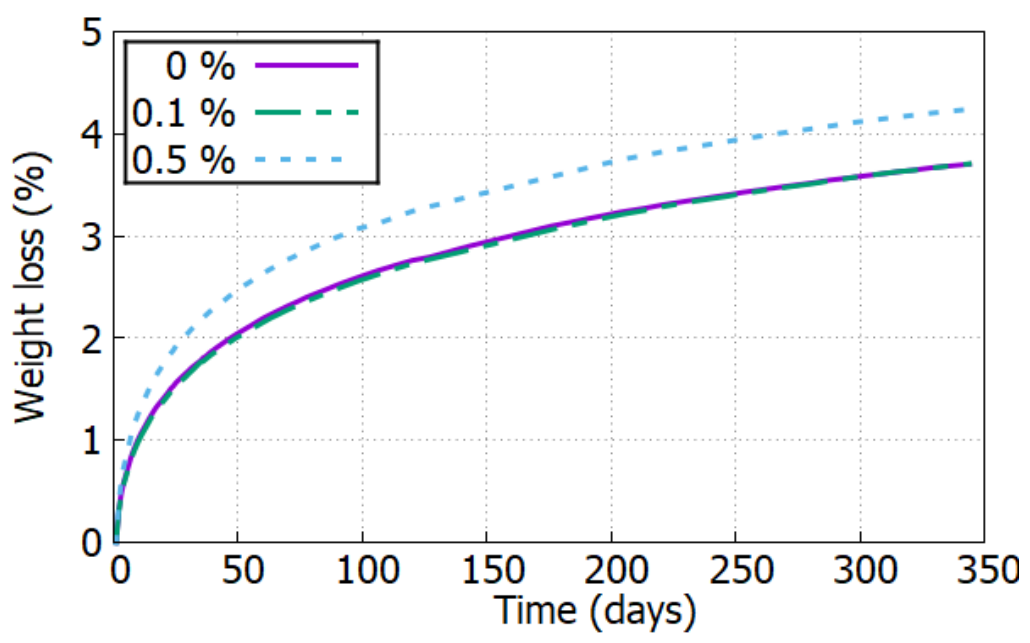

Fig. 4: Weight loss variation over time 


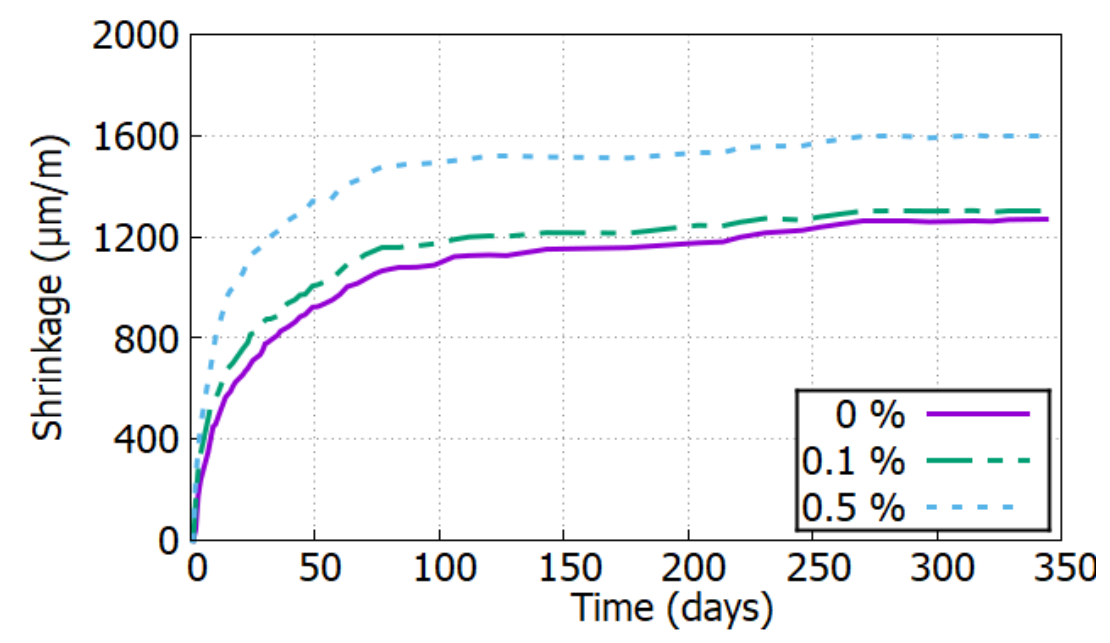

Fig. 5: Shrinkage variation over time

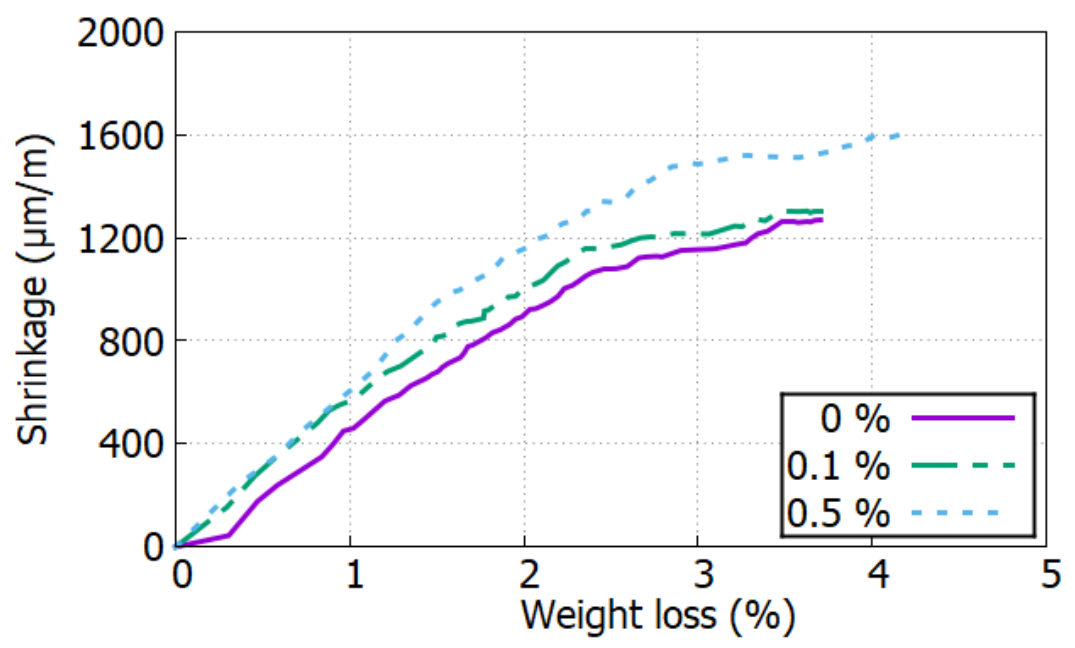

Fig. 6: Shrinkage as a function of weight loss

\subsection{Complex impedance variation during drying}

Every sample has a complex volume impedance $Z$, with a real part $\left(Z^{\prime}\right)$ and imaginary part $\left(Z^{\prime \prime}\right)$, related by the following equation:

$$
\mathrm{Z}=\mathrm{Z}^{\prime}+\mathrm{i} \mathrm{Z}^{\prime \prime}
$$

Fig. 7 and 8 show the evolution of the real and imaginary parts of the impedance of the reference mortar as a function of time, shrinkage and weight loss for different measurement frequencies across the frequency range. The real and absolute value of imaginary impedance increased 
steadily with drying for almost 140 days (corresponding to shrinkage and weight loss values equal to $1.150^{*} 10 \mathrm{E}-3 \varepsilon$ and $3 \%$ respectively), before taking on a steep slope beyond this threshold. The real impedance increased from approximately 10E3 $\Omega$ at the beginning, reaching values almost 100 times higher with water loss by the end of the drying time (between 4 and $7^{*} 10 \mathrm{E} 4 \Omega$ ). The absolute values of the imaginary part followed the same pattern, increasing considerably during drying. The effect of water loss can be seen in the increased impedance values, since mortar is supposed to be an insulative material with higher resistivity compared to water.

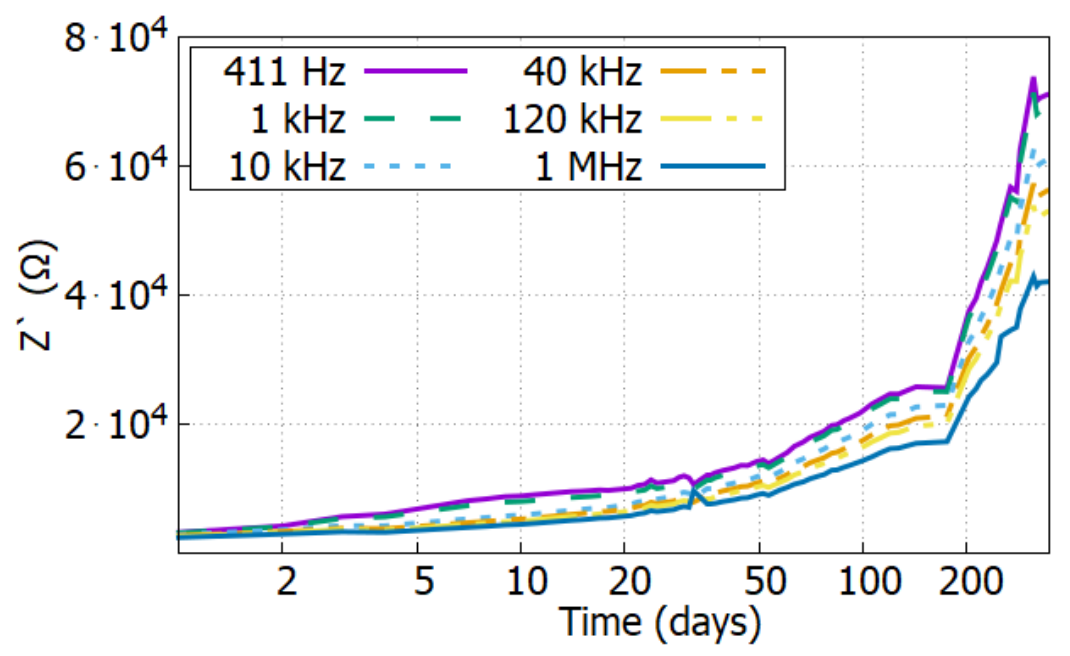

(a)

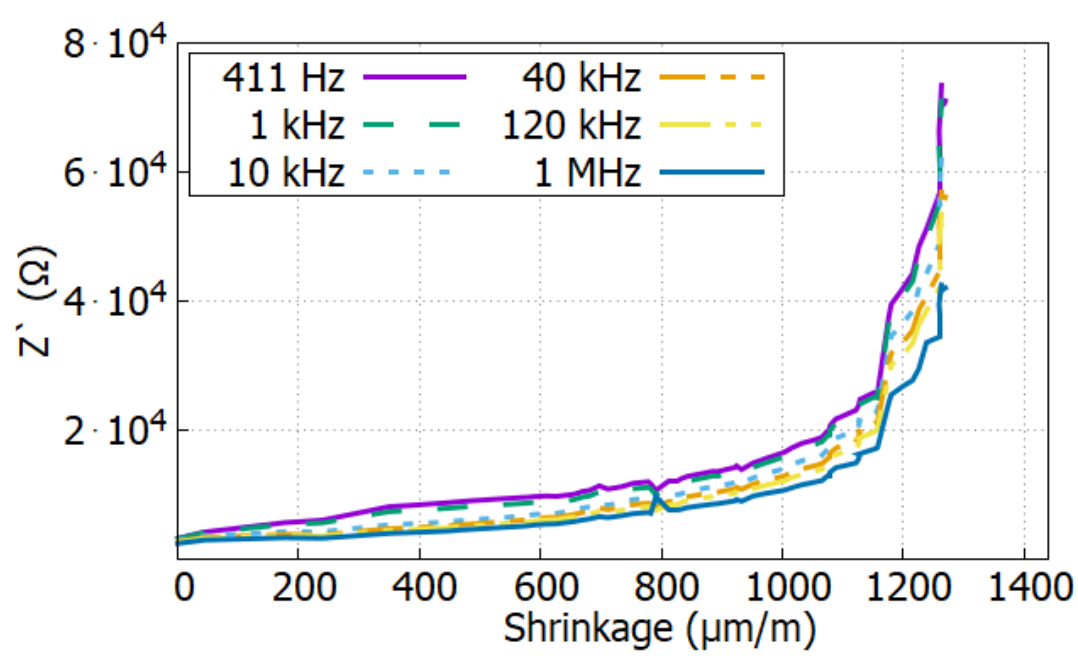

(b) 


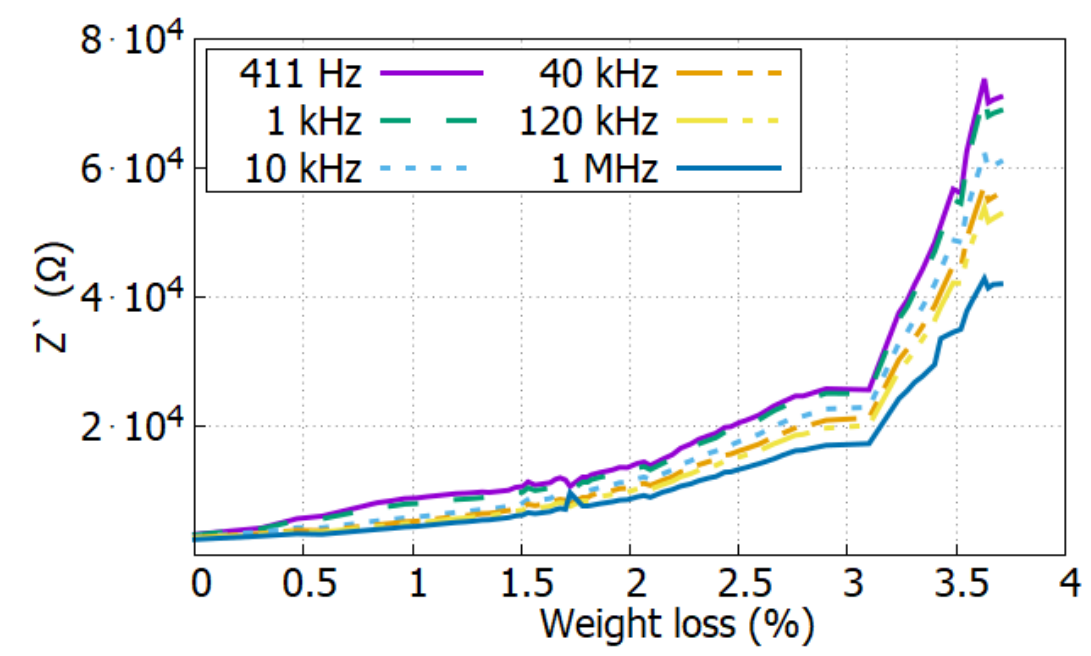

(c)

Fig. 7: Real impedance of reference mortar as a function of (a) Time, (b) Shrinkage and (c) Weight loss

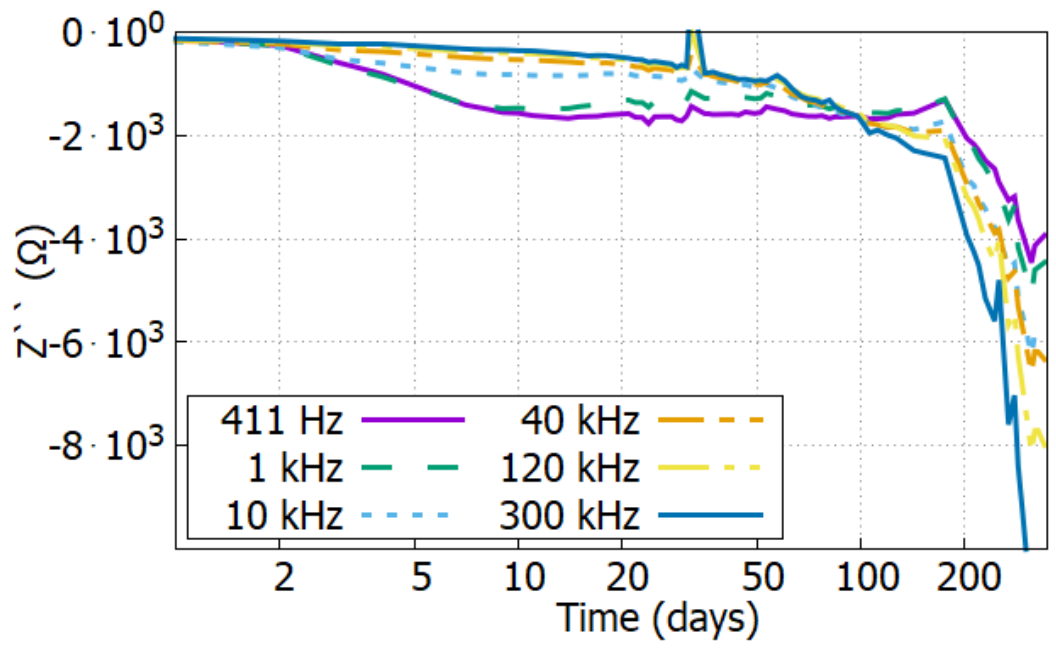

(a) 


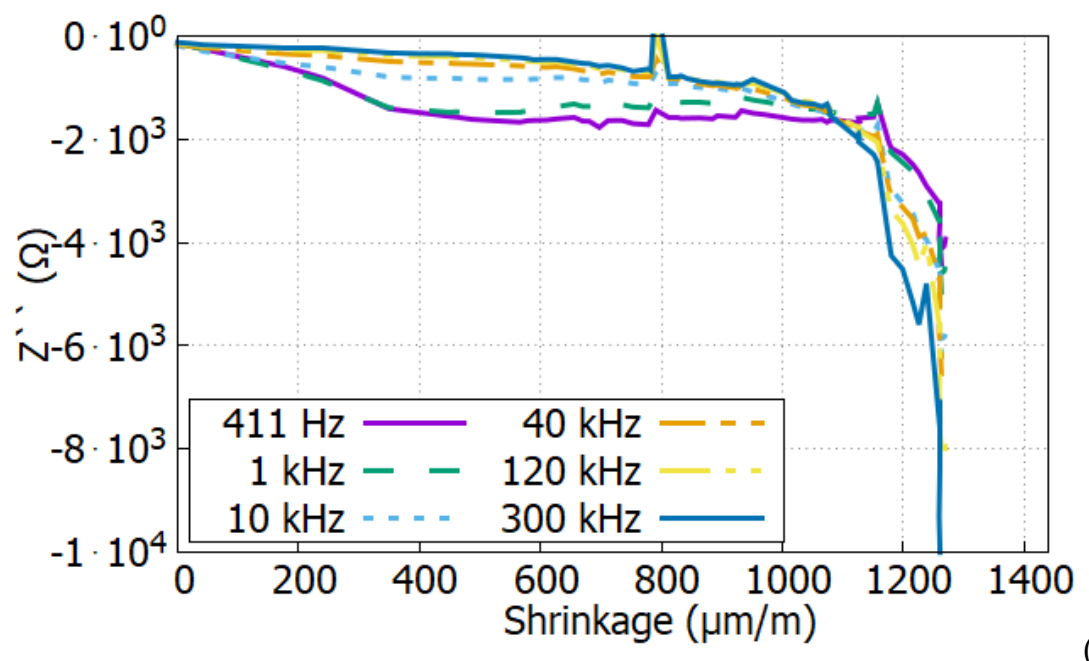

(b)

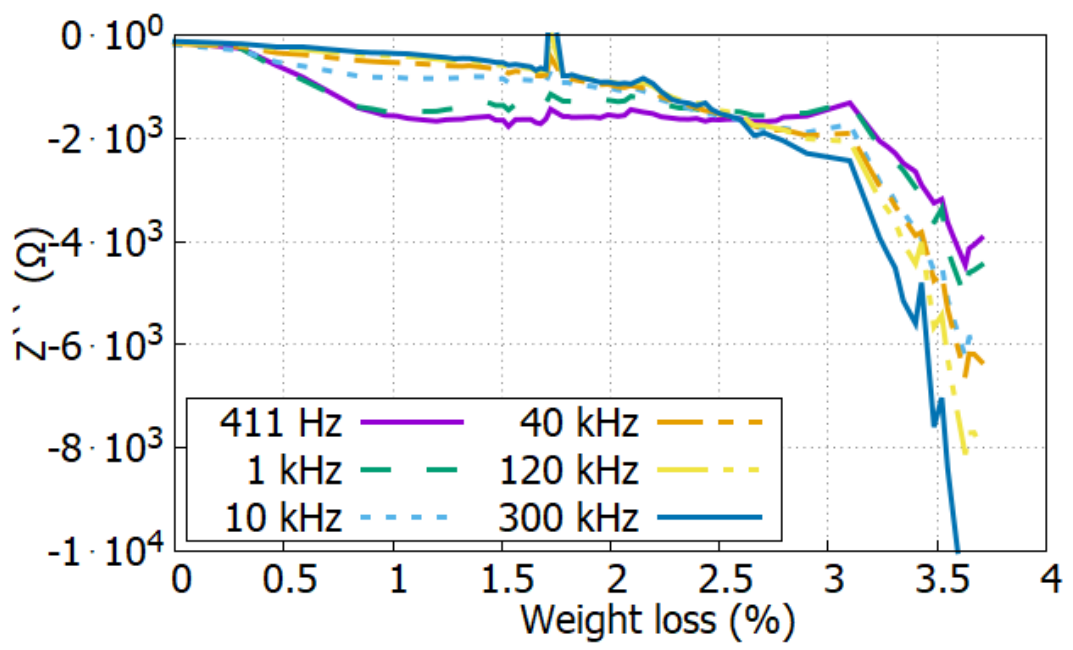

(c)

Fig. 8: Imaginary impedance of reference mortar as a function of (a) Time (b) Shrinkage and

(c) Weight loss

Fig. 9 and 10 show the influence of the fibers on the evolution of the real and imaginary parts of the impedance for mortar with a fiber volume fraction of $0.1 \%$. The presence of conductive carbon fibers affected the electrical response in the initial absolute values of impedance, and their evolution with time. At $t=0$, for the different measurement frequencies, the real impedance values became of the order of $10 \mathrm{E} 2 \Omega$ for frequencies lower than $1 \mathrm{kHz}$ and $10 \mathrm{E} 1 \Omega$ for frequencies higher than $10 \mathrm{kHz}$, and imaginary impedance of the order of $10 \mathrm{E} 1 \Omega$, instead of $10 \mathrm{E} 3 \Omega$ and 10E2 $\Omega$ 
respectively for the real and imaginary impedances of the reference mortar. Real impedance decreased with increasing frequency due to the reduction of the electrode and electrolyte polarization effect [43][44]. With drying, the evolution of impedance values is dependent on the measurement frequency. At low frequencies $(<1 \mathrm{kHz})$ the real impedance is reduced with time, while for frequencies greater than $1 \mathrm{kHz}$, it increases. At $1 \mathrm{kHz}$, variation of real impedance is limited; the gaps between real impedances measured at low and high frequencies are reduced, and values from both sides tend towards real impedance measured at $1 \mathrm{kHz}$.

In contrast, regarding the imaginary impedance values, drying reduced the capacitive effect, where the absolute value of the imaginary part shown in Fig. 10 as a function of time, shrinkage and weight loss, is reduced steadily. Similarly, concerning the imaginary impedance measured at different measurement frequencies, the gap between the measured imaginary impedances is reduced and the values seem to tend toward a narrow range closer to 0 .

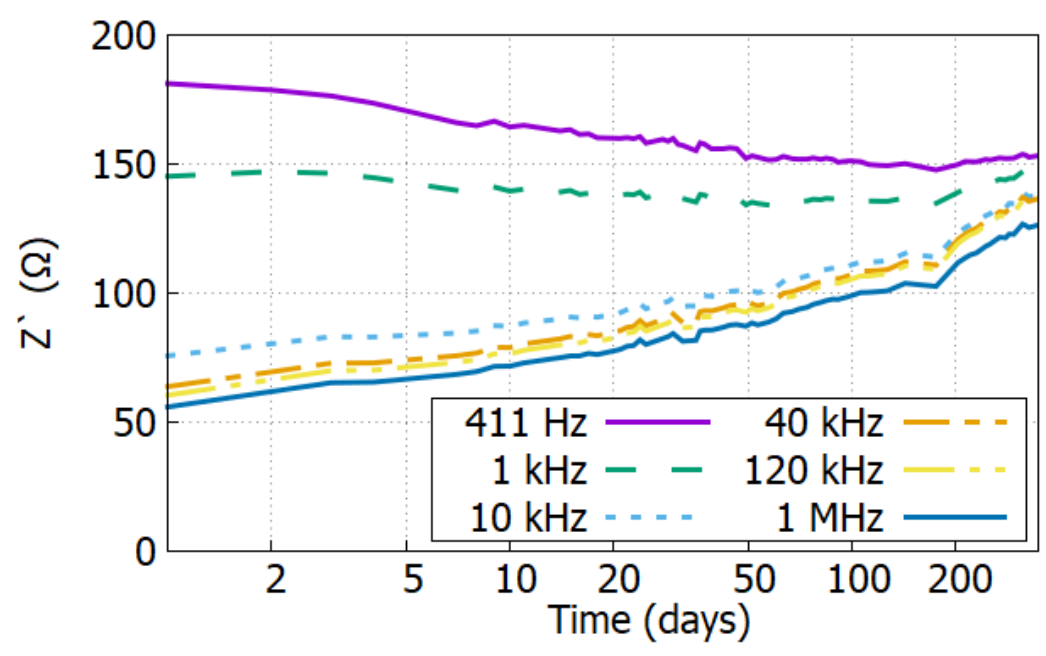

(a) 


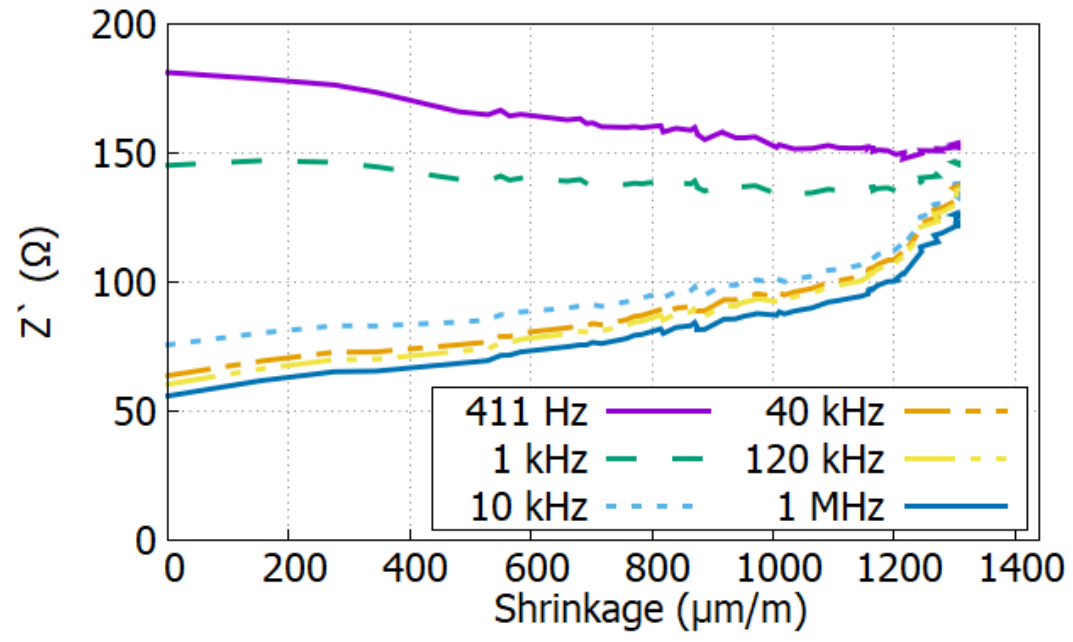

(b)

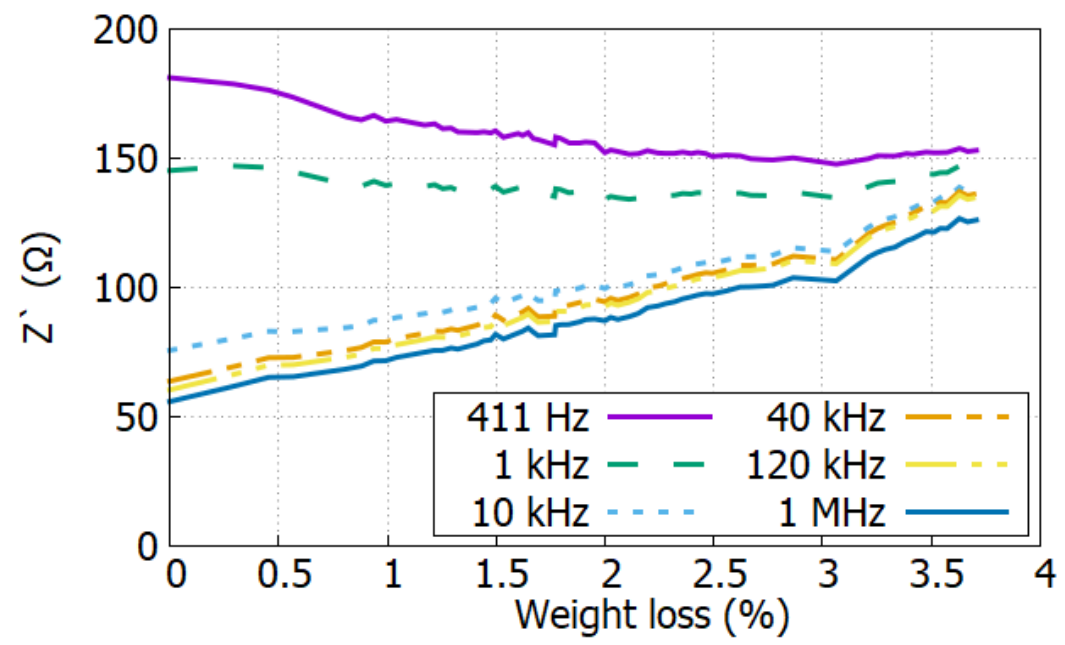

(c)

Fig. 9: Real impedance of low-fiber mortar as a function of (a) Time, (b) Shrinkage and (c) Weight loss 


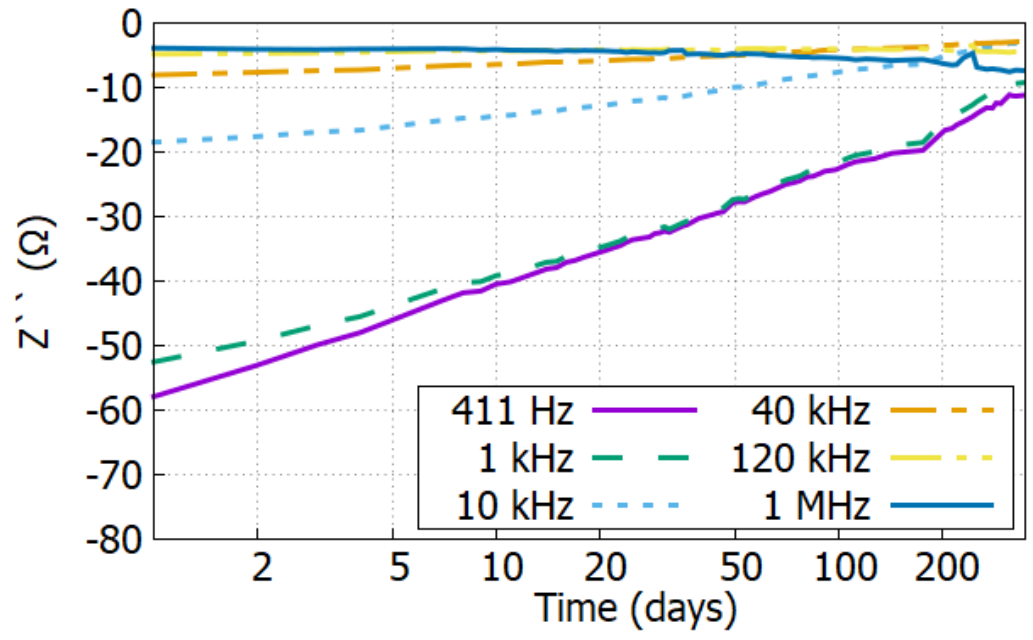

(a)

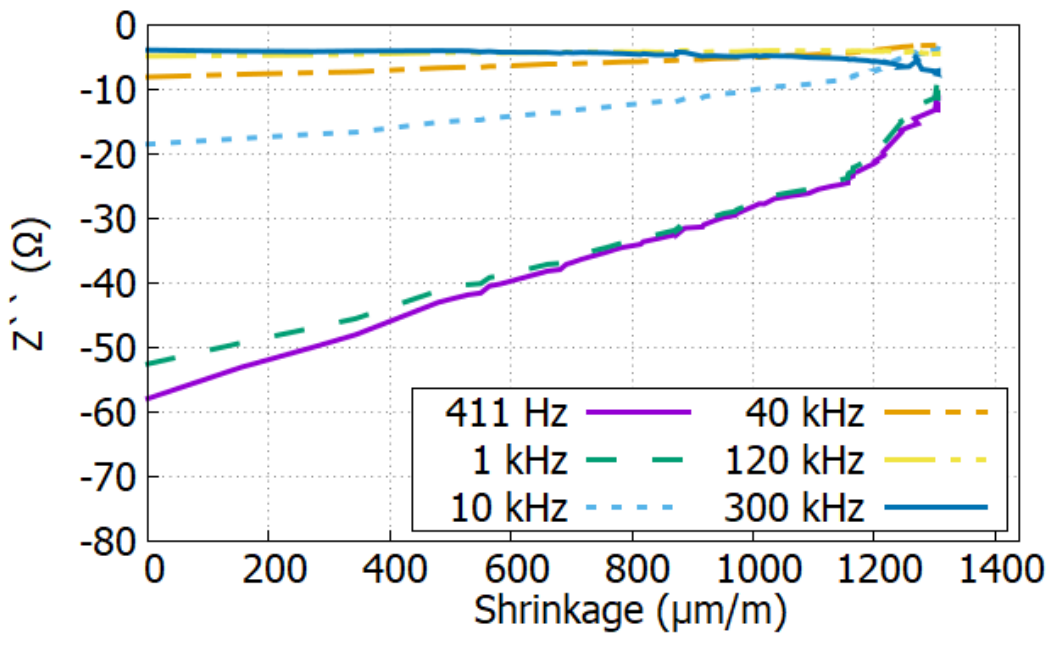

(b)

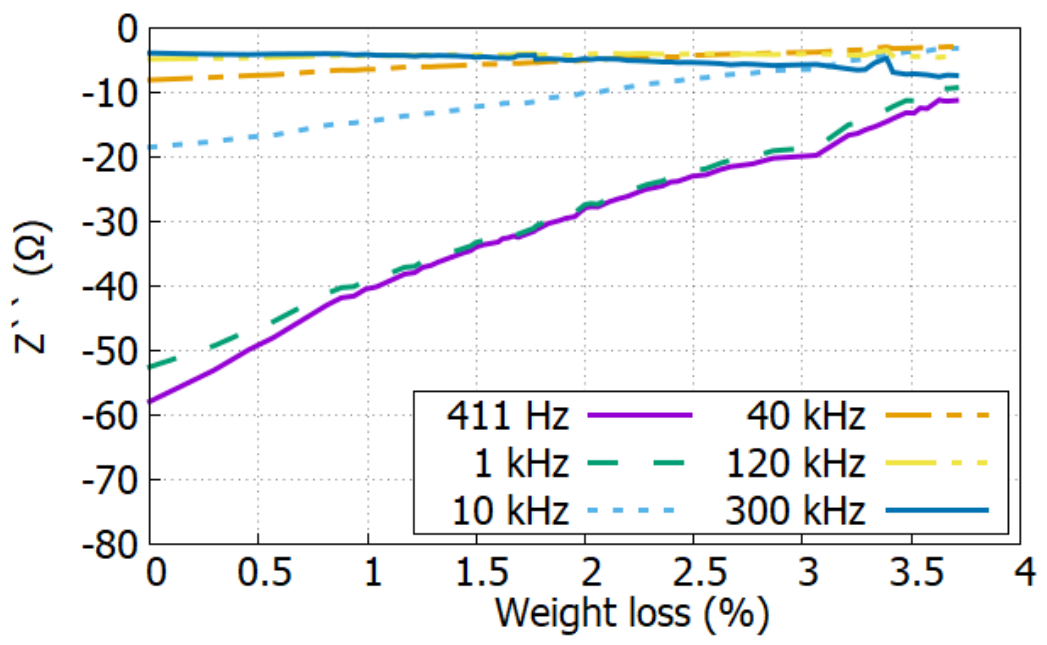

(c) 
Fig. 10: Imaginary impedance of low-fiber mortar as a function of (a) Time, (b) Shrinkage and

\section{(c) Weight loss}

A similar behavior is seen for mortar with a FVF of $0.5 \%$, as shown in Fig. 11 and 12: for frequencies lower than $40 \mathrm{kHz}$ once again, more clearly in this case, the real impedance values seem to tend towards a single value equal to $16 \Omega$ independently of the measurement frequency, and the absolute value of the imaginary part of the impedance decreases sharply during drying towards $0 \Omega$ across the whole frequency range. This means at the end of drying period, the complex impedance measured throughout the frequency range is homogenized, with a real part of around $16 \Omega$ and an imaginary part equal to 0 .

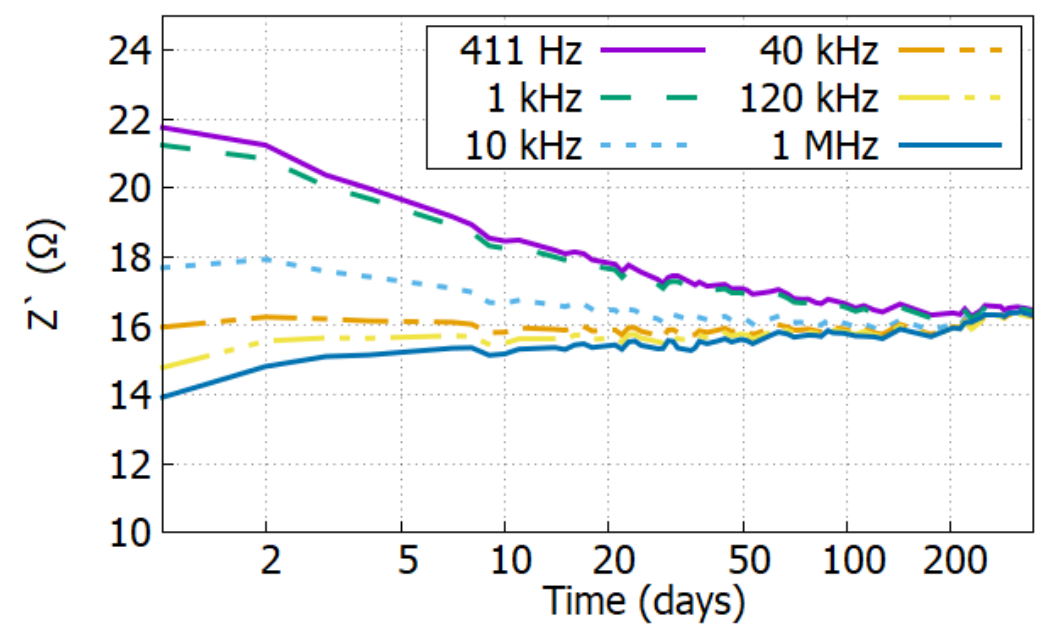

(a) 


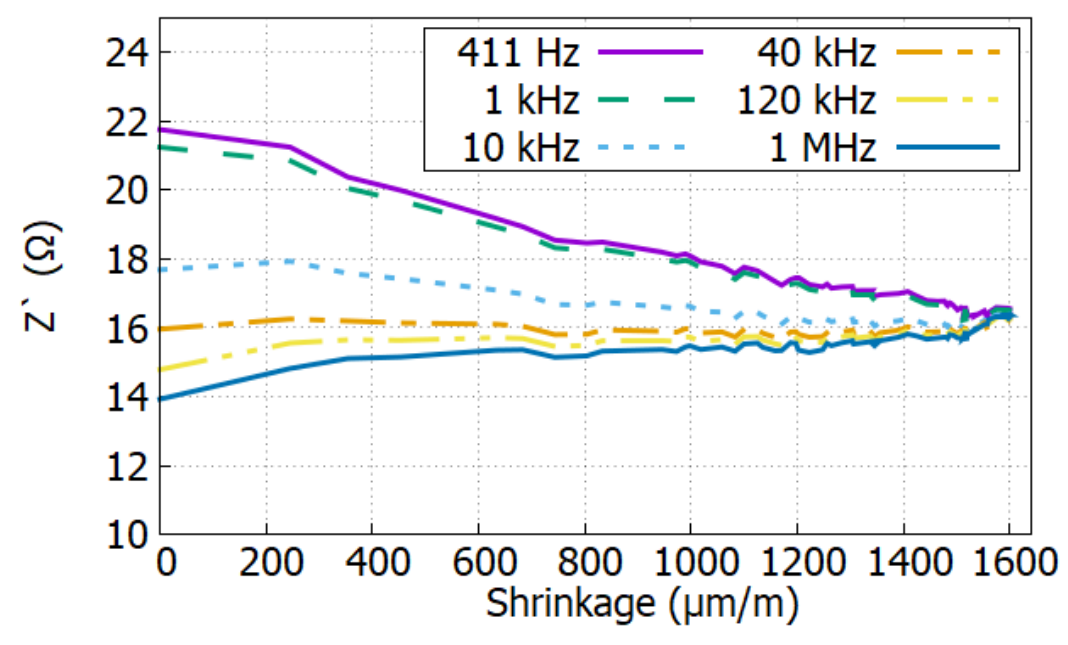

(b)

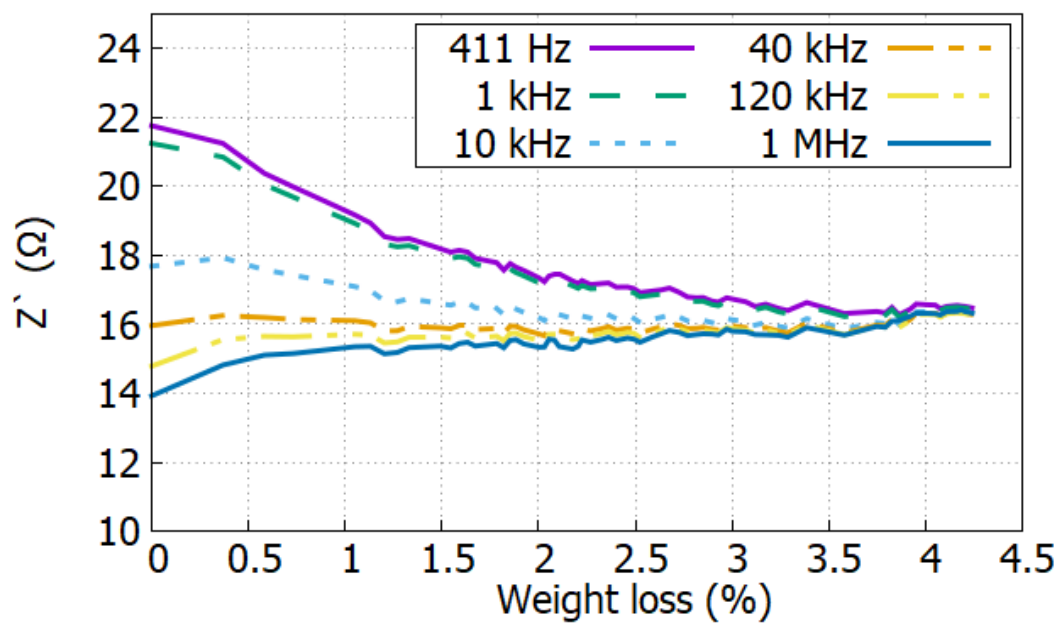

(c)

Fig. 11: Real impedance of high-fiber mortar as a function of (a) Time, (b) Shrinkage and (c) Weight loss 


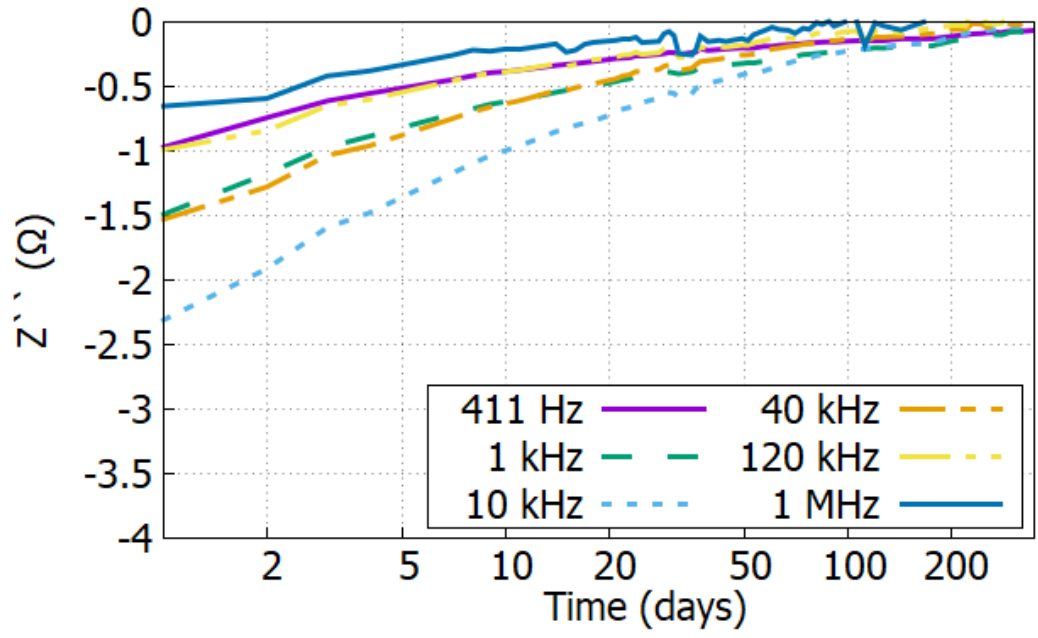

(a)

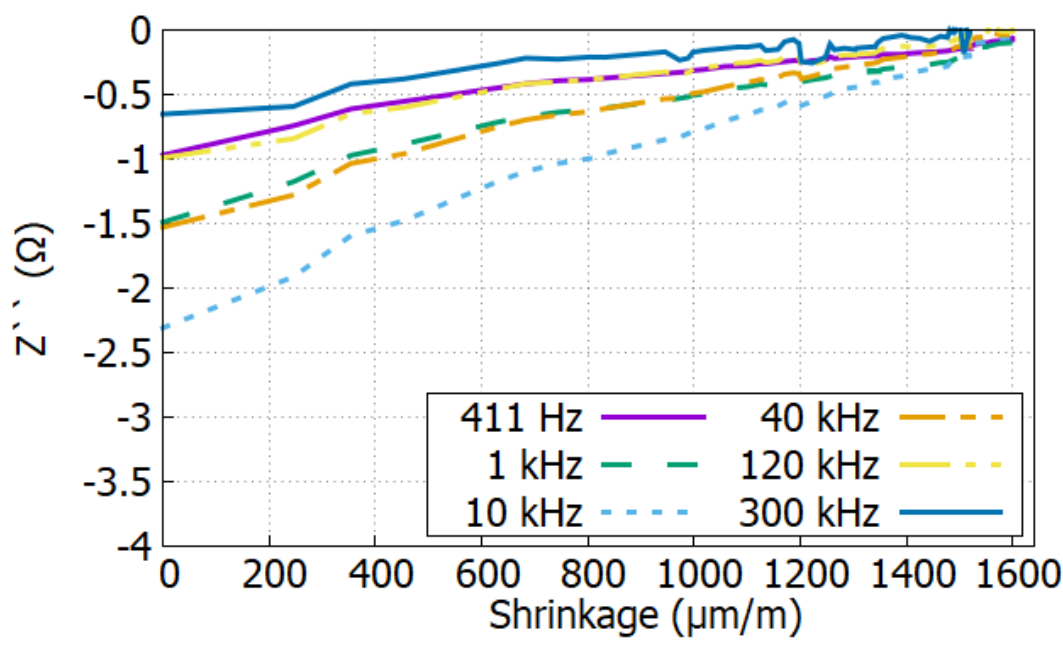

(b)

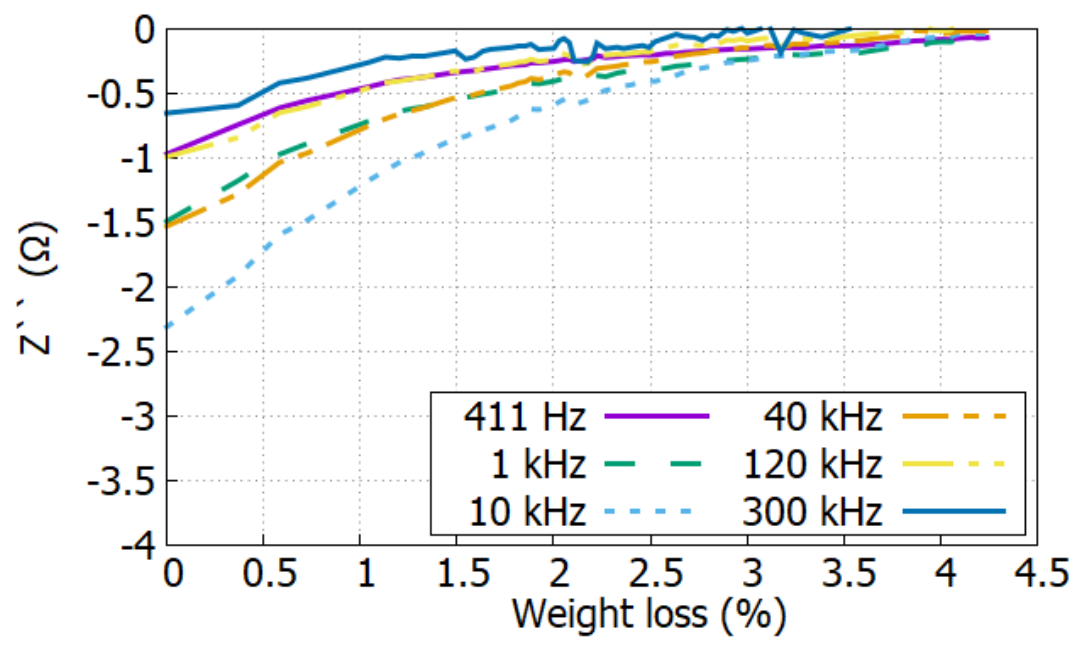

(c) 
Fig. 12: Imaginary impedance of high-fiber mortar as a function of (a) Time, (b) Shrinkage and

\section{(c) Weight loss}

\section{Uncertainties caused by drying on the mechanical properties}

In the following section, the dispersion of the real impedance will be quantified using equations in section 2.3. The most stable frequency interval (presenting the lowest relative standard deviation of real impedance variation over time) contains potential monitoring frequencies, since perturbations of real impedance caused by drying would be reduced - i.e. less interference with sensing of mechanical loads. To quantify the perturbation caused by drying on the sensing of compression loads, the standard deviation of the real impedance values over time is compared to the fractional variation under compression cycles.

\subsection{Stability of impedance over time as a function of frequency}

The values of $\sigma$ and $c_{v}$ for different mortars are shown in Fig. 13. For the reference mortar, the value of the real impedance increases and does not settle at any measuring frequency, presenting no stable frequency interval. On the other hand, for fiber-reinforced mortars, there seems to be a measurement frequency at which the value of the real impedance remains almost constant throughout the drying process. For mortar with a FVF of $0.1 \%$, a stable frequency interval was detected during drying, around $1 \mathrm{kHz}$ with $\sigma=3.6 \Omega$ and $\mathrm{c}_{v}=2.59 \%$, whereas for mortar with a FVF of $0.5 \%$, this measurement frequency appears to be around $40 \mathrm{kHz}$ with $\sigma=0.18 \Omega$, corresponding to a relative standard deviation $\mathrm{c}_{\mathrm{v}}=1.12 \%$. 


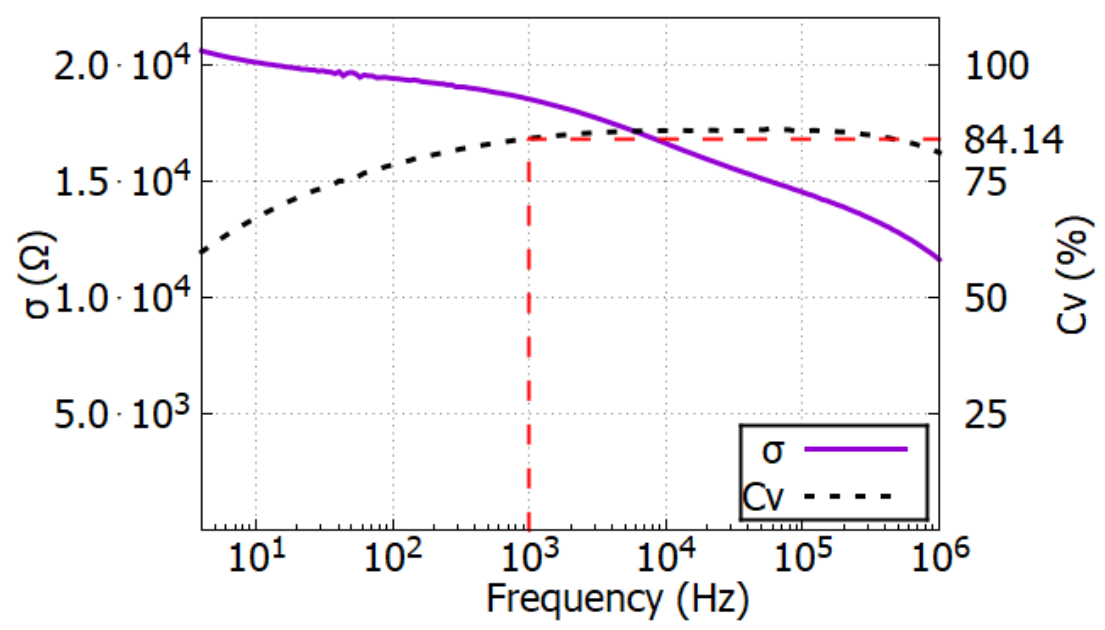

(a)

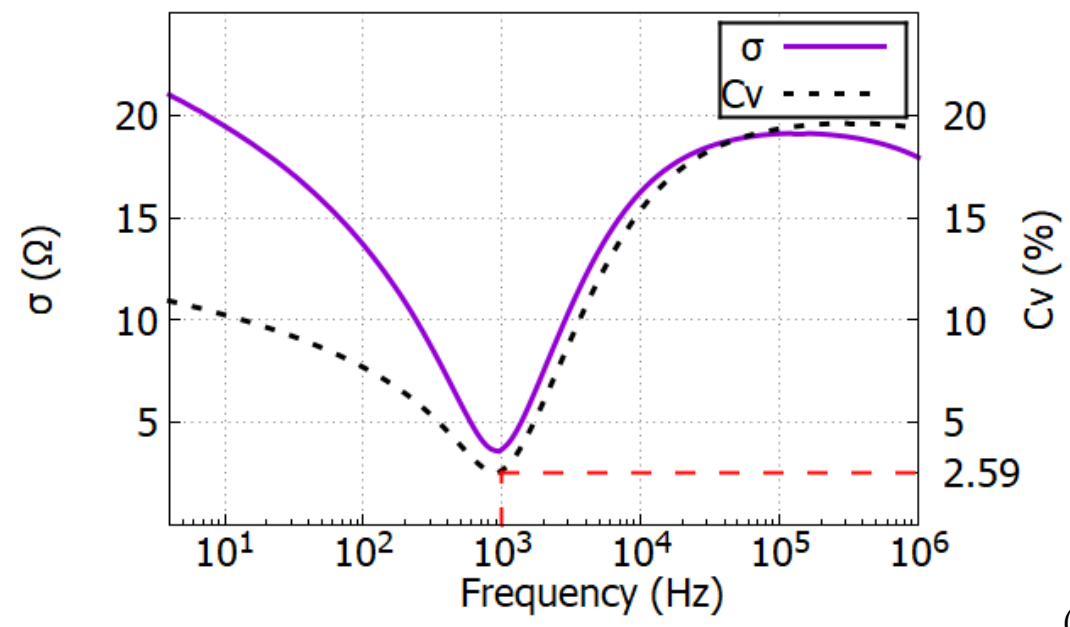

(b)

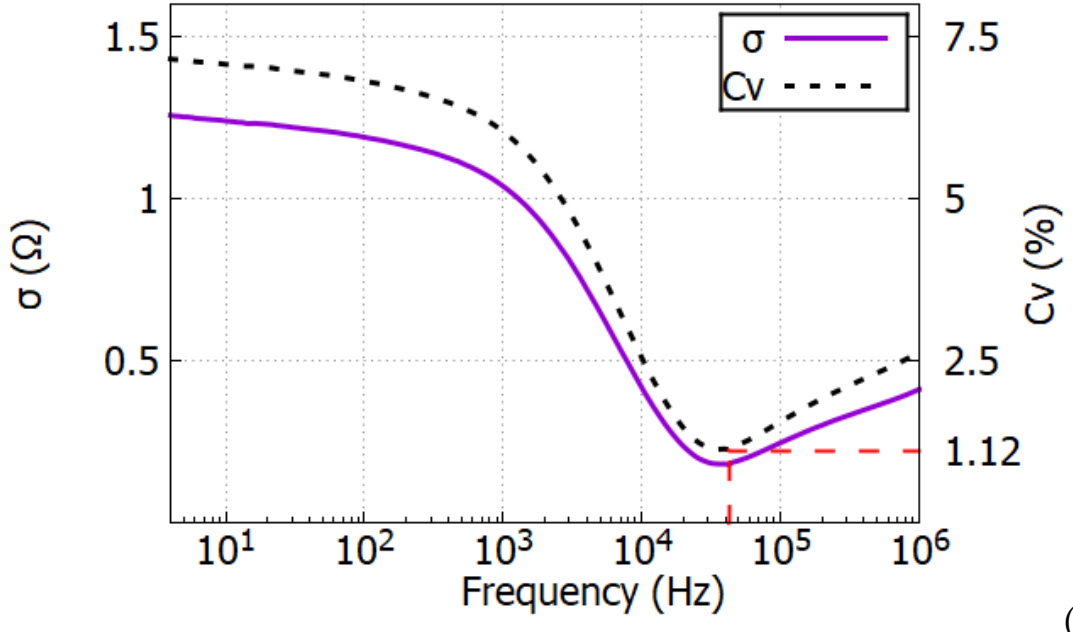

(c) 


\section{Fig 13: Standard deviation and relative standard deviation of (a) Reference mortar,}

\section{(b) Low-fiber mortar and (c) High-fiber mortar}

\subsection{Piezoresistivity}

Considering the real impedance variation over the frequency range illustrated in Fig. 13, selfsensing of the different formulations was tested at the frequencies exhibiting the lowest standard deviation value over time. The purpose of this choice was to ensure self-sensing behavior over time, where drying effects on measured values are as slight as possible. For low-fiber mortar, selfsensing behavior is tested at $1 \mathrm{kHz}$; high-fiber mortar is tested at $40 \mathrm{kHz}$; and for the reference mortar, since there is no stable frequency, monitoring at $1 \mathrm{kHz}$ was adopted). The fractional variation of real impedance $\left(\Delta Z^{\prime} / Z^{\prime}\right)$ under compression cycles is shown in Fig. 14 (the purple curve shows the compression cycles over time and the green curve the fractional variation of real impedance over time under the compression cycles). For non-fibrous mortar, note the poor sensitivity to external loads, with a high noise-to signal ratio. The presence of fibers enhanced the response by reducing the noise-to-signal ratio and increasing the fractional variation of impedance as a function of the compression loads. Drying in the absence of fibers would cause $84.14 \%$ of relative standard deviation, which is considerably higher than real impedance fractional variation under $5 \mathrm{MPa}$ of compression. In the presence of fibers, monitoring low-fiber mortar at $1 \mathrm{kHz}$ and high-fiber mortar at $40 \mathrm{kHz}$ (corresponding respectively to their stable frequencies) would drastically reduce the uncertainty in piezoresistive precision. In the case of low-fiber mortar, the uncertainty would be around $2.59 \%$, and it reach $1.12 \%$ in the case of highfiber mortar. Coupling the use of fibers with corresponding stable frequencies has proved effective in enhancing the accuracy of sensing. 


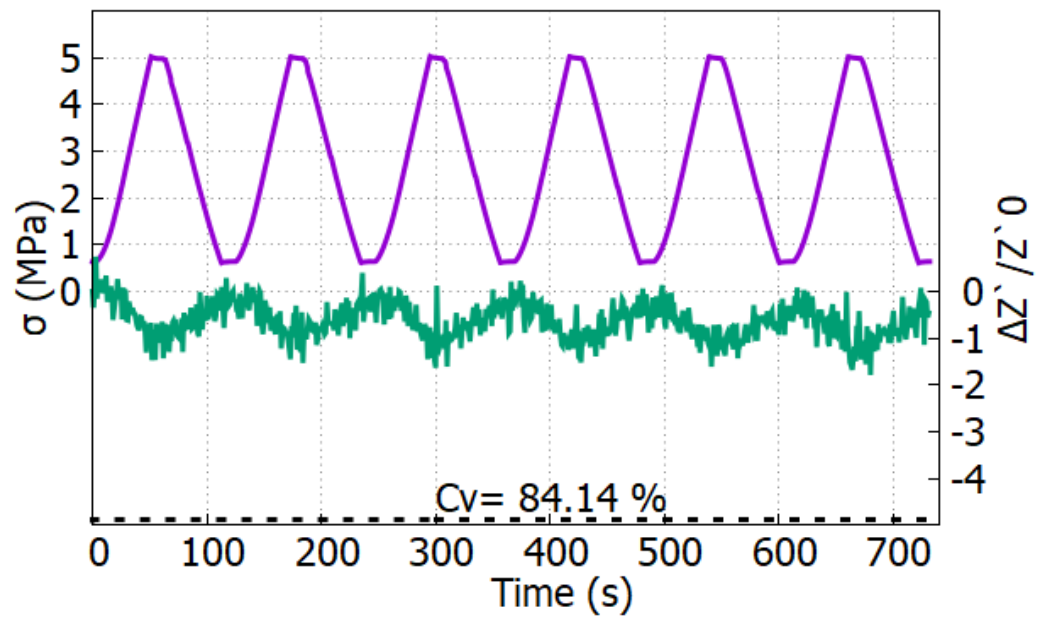

(a)

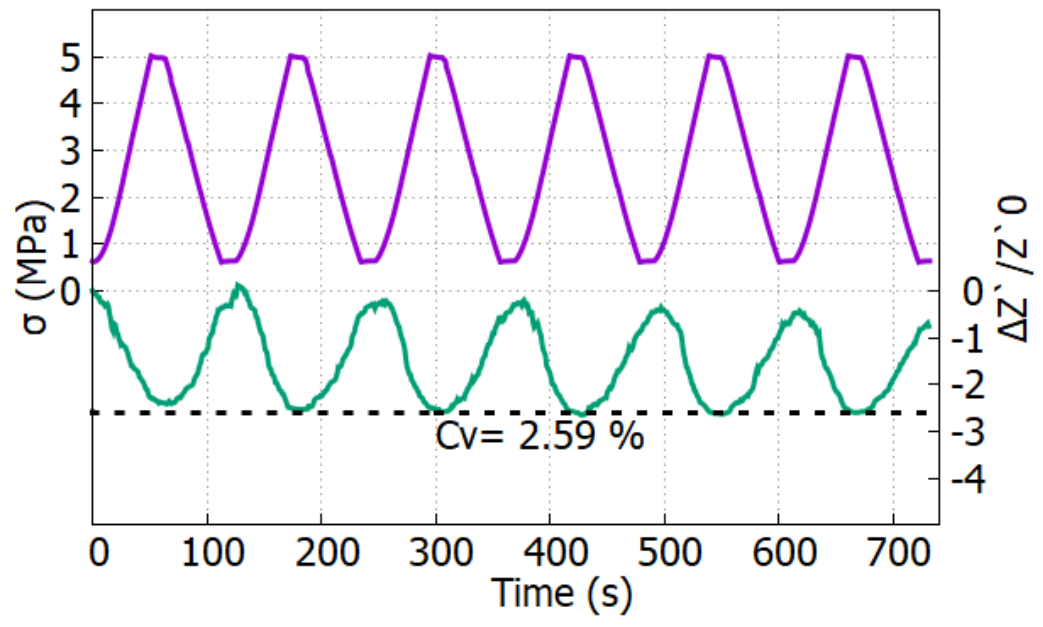

(b)

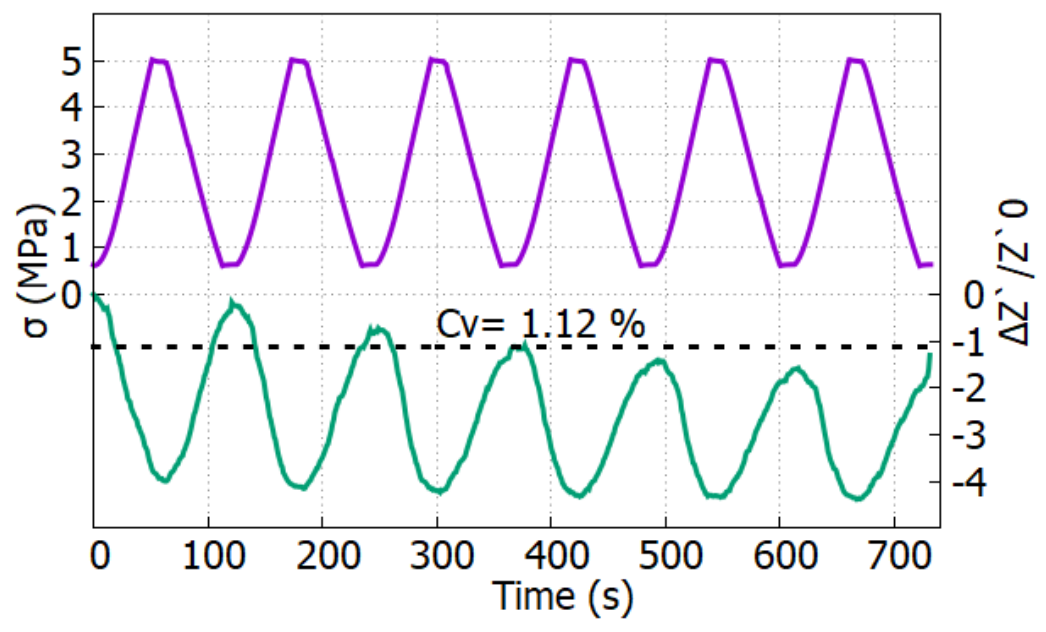

(c) 


\section{Fig. 14: Real impedance variation under compression cycles for (a) Reference mortar,}

(b) Fiber volume fraction $0.1 \%$ and (c) Fiber volume fraction $0.5 \%$

\section{DISCUSSION}

The linear relationship between shrinkage and weight loss observed at the beginning of drying proves the direct effect of the decrease in water content in the capillary pores on the volume reduction of cementitious materials. In a second phase of drying, the shrinkage attributable to weight loss is reduced, since the main network of capillary pores is highly unsaturated [26]. Carbon fibers are expected to reduce shrinkage, especially at a young age when curing is not carried out under wet conditions. However, for this study, drying shrinkage was studied after 28 days of wet curing and with low amounts of fibers. Similarly, in other studies [39], carbon fibers were only able to reduce shrinkage when their dosage exceeded a certain threshold (fiber volume fraction of $0.4 \%$ ). The increased shrinkage of mortars in the presence of carbon fibers may be related to the use of additional superplasticizer for fibrous mortars, which increased the initial liquid phase and consequently water loss during drying, leading to higher shrinkage values. In addition, in the presence of a high dose of carbon fibers, previous studies [39][45][46] have shown possible agglomeration of fibers, which would increase the entrained air volume.

With respect to electrical properties, in the case of the reference mortar ( $0 \%$ fibers), the conductivity of composites is estimated using the following equation [27][30]:

$$
\sigma_{\mathrm{t}}=\Sigma \sigma_{\mathrm{i}} \Phi_{\mathrm{i}} \beta_{\mathrm{i}}
$$

where $\sigma_{\mathrm{i}}, \Phi_{\mathrm{i}}$ and $\beta_{\mathrm{i}}$, respectively, are the electrical conductivity, volume fraction and connectivity factor of each constitutive component (i) of the non-fibrous mortar. In the case of partially saturated cementitious materials, since the conductivity depends mainly on the liquid phase, the equation was simplified to depend solely on water properties:

$$
\sigma_{\mathrm{t}}=\sigma_{0} \Phi \beta
$$


where $\sigma_{0}$ is the conductivity of pore fluid, $\Phi$ is the total liquid-filled porosity and $\beta$ is the pore connectivity.

$\sigma_{0}$, the conductivity of water in porous fluid, increases with time, since the volume of the liquid phase is reduced by water migration; therefore, ion concentration increases, causing a corresponding increase of this parameter. Weight loss would reduce the volume $\Phi$ of water present in capillaries. Water loss combined with the densification of the matrix structure reduce the connectivity between capillary pores, consequently reducing the factor $\beta$. Even though the conductivity of water increases over time, water volume reduction and increased discontinuities in capillary pores would reduce the conductivity of this network, and consequently adversely affect the conductive paths within the whole material.

For fibrous mortars, efficiency of fibers in reducing real and imaginary impedances (as shown in Fig. 9-12) is due to the effectiveness of fibers in creating conductive paths, promoting electronic conduction in addition to the ionic depending on water presence. Fibers efficiency is creating conductive paths depends on their volume fraction and aspect ratio. The percolation threshold of carbon fibers used was examined experimentally in a previous study [39]; it was estimated at between 0.1 and $0.2 \%$ of the carbon fiber volume fraction. This study validates their efficiency at $0.1 \%$ in reducing the impedance of fibrous mortar.

During drying, the shrinkage of the cementitious matrix causes relative deformation on the interfaces between the different phases of the material: the sand-cement paste and fibers-cement paste interfaces. Thus, although the real impedance of the cementitious matrix increases during drying due to the progressive loss of water in capillary pores, a decrease in the apparent real impedance of the mortar is observed at frequencies lower than $1 \mathrm{kHz}$ for low-fibrous mortar and $40 \mathrm{kHz}$ for high-fibrous mortar. This could be related to a shrinkage effect, which favors contact between adjacent fibers [47] and thus improves electronic conductivity. It may also be related to 
the reduction of the dipole polarization or orientation of water molecules at frequencies smaller than $1 \mathrm{kHz}$, stemming from the reduction of the amount of water present in the mortar, leading to a decrease in real impedance value. The increase in the real impedance at high frequency was attenuated by the presence of $0.5 \%$ of fiber volume fraction, given the greater presence of the fibers, which favored conductivity through the percolated chains and consequently reduced the effect of the progressive loss of ionic transport of electric charges.

During drying, the capacitive behavior of the mortar disappears, and it begins to exhibit quasiperfect resistive behavior, more pronounced in the case of fiber-saturated mortar $(0.5 \%)$ : at the end of drying period, value of the real impedance is quasi-constant over the entire range of measurement frequencies studied, in addition to an imaginary value equal to 0 .

Fitting mortar's electrical behavior on R-C circuit was done previously in absence of conductive fibers, where the behavior of mortar is identified as a succession of two resistors in parallel representing respectively the resistance of water phase and liquid phase, this circuit in series with $\mathrm{R}-\mathrm{C}$ circuit representing the solid-liquid interface [48]. Effect of conductive fibers presence on he fitting $\mathrm{R}-\mathrm{C}$ circuit, in case of percolation, is to add a parallel R-C circuit with small components values [49].

The effect of drying on those circuits depends on fiber presence. In absence of fibers, drying effect was just quantitative, i.e., increase liquid phase resistivity due to introduced discontinuities and creasing in solid-liquid interface impedance demonstrated by bigger imaginary values. Drying of cementitious matrix in presence of fibers on those corresponding circuits had an additional effect, where shrinkage promotes fibers contact and consequently reduce the impedance value of he parallel, and consequently, pushing this path to dominate current flow thanks to its high conductivity, and transforming the suitable circuit model to a simple resistor with low resistance values. 
For piezoresistivity, the absence of fibers caused poor sensing of compression cycles, which illustrates the importance of fiber inclusion to develop self-sensing behavior for the cementitious matrix. The piezoresistivity mechanism is triggered by deformation due to compressive cycles. Sensing mechanisms depend heavily on the proportion of carbon fibers. For non-fibrous mortar, poor sensitivity was predicted, since it depends mainly on the piezoresistivity of the cement matrix, which is already supposed to be poor. With low-fiber mortar, the presence of fibers leads to more efficient piezoresistive behavior, where under deformation, the distance between fibers is reduced, triggering more probable percolated paths and enhancing tunneling conduction. Drying shrinkage was proved to possibly cause uncertainties in sensing mechanisms, due to its effect on material's impedance that interferes with the application of external mechanical loads. Coupling the presence of fibers with the adoption of an $\mathrm{AC}$ impedance with frequencies presenting minimal perturbations would reduce the uncertainties related to the evolution of material structure during sensing of external loads, thereby significantly enhancing the precision of the sensing response over time.

\section{CONCLUSION}

This study presented the differential effect of drying on impedance variation over a wide

requency range, that permitted a potential monitoring application effective in minimizing the secondary effects of drying on self-sensing, by coupling fiber presence in cementitious matrix with corresponding frequencies presenting low real impedance variation with time. Drying

period studied over 344 days allowed to reach the following statements

The impedance of mortar has been shown to be affected by drying shrinkage. Its effect is

heavily dependent on the presence and volume fraction of fibers. For the reference mortar, in the absence of fibers, the decrease in water content leads to an increase in impedance during drying, in both real and imaginary parts, across the whole frequency 
range. It is related to the reduction of the degree of saturation of the interstitial solution in

the capillary pore network, creating discontinuities in the conductive network, thus

preventing the ionic transport of electric charges. The electrical impedance, though,

shows no stabilization phase, at any of the measurement frequencies

The presence of conductive fibers changes the variation of the impedance over time; $\mathrm{i}$

becomes frequency dependent. The real impedance of fibrous mortar decreases at low

frequencies, unlike the reference mortar, and increases at high frequencies, but to a much

lesser extent in the presence of fibers this time. The decrease at low frequencies could be

related to a positive effect of the shrinkage on the conductivity of the fiber network,

whereas the increase at high frequencies would be a consequence of the decrease in water

content. However, this increase in real impedance at high frequencies is much reduced by

the presence of the fibers, since the conductive network allows the electronic transport of

the charges in the absence of an interstitial solution in the capillary porosity of the

material. The difference between the real impedance values measured at low and high

frequencies is reduced. Thus, the real impedance values seem, in the presence of fibers, to

tend towards a single value independent of the measurement frequency.

The capacitive behavior of fibrous mortar gradually wanes during the drying process,

especially in the presence of enough fibers, bringing imaginary impedance with drying to

across the frequency range; therefore, a fibrous mortar adopting almost resistive

\section{behavior.}

A measuring frequency range shows almost constant real impedance values throughout

the drying process. However, this frequency is different for mortars with FVFs of 0.1 and

$0.5 \%$ : it appears to be about 1 and $40 \mathrm{kHz}$, respectively. 
For mortars containing carbon fibers, the measurement of electrical impedance can help monitor external actions such as mechanical loading or temperature variation. However, as it stands, any variation in the degree of saturation of the capillary porosity risks distorting the use of electrical measurements for monitoring purposes; the use of certain frequencies, belonging to the range presenting more stability of real impedance with time could limit the effects of aging, and consequently represents a step towards reducing the interference between drying and self-sensing behavior.

\section{Credit authorship contribution statement}

Hamza Allam: Methodology, Formal analysis, Investigation, Writing - Original Draft.

Francois Duplan: Conceptualization, Methodology, Validation, Investigation, Supervision, Writing - review.

Jean-Pierre Clerc: Investigation

Sofiane Amziane: Conceptualization, Methodology, Validation, Investigation, Supervision, Writing - review \& editing,

Yves Burtshell: Validation, Supervision - review.

\section{Declaration of Competing Interest}

The authors declare that they have no known competing financial interests or personal relationships that could have appeared to influence the work reported in this paper.

\section{REFERENCES}

[1] F.J. Baeza, O. Galao, E. Zornoza, P. Garcés, (2013) Effect of aspect ratio on strain sensing capacity of carbon fiber reinforced cement composites, Materials \& Design, Vol 51, 1085-1094, DOI: https://doi.org/10.1016/j.matdes.2013.05.010. 
[2] M. Chiarello, R. Zinno, (2005) Electrical conductivity of self-monitoring CFRC, Cement and Concrete Composites, Vol 27, Issue 4, 463-469, https://doi.org/10.1016/j.cemconcomp.2004.09.001.

[3] X. Liu, S. Wu, (2009) Research on the conductive asphalt concrete's piezoresistivity effect and its mechanism, Construction and Building Materials, Vol 23, Issue 8, 2752-2756, https://doi.org/10.1016/j.conbuildmat.2009.03.006.

[4] F. Azhari and N. Banthia, (2012) Cement-based sensors with carbon fibers and carbon

nanotubes for piezoresistive sensing, Journal of Materials Science, Vol 34, Issue 7, 866-873 DOI:

https://doi.org/10.1016/j.cemconcomp.2012.04.007

[5] B. Han, X. Yu, J. Ou, (2010) Effect of water content on the piezoresistivity of MWNT/cement composites, Journal of materials science, Vol 45, 3714-3719 (2010). https://doi.org/10.1007/s10853-

\section{$\underline{010-4414-7}$}

[6] D.D.L. Chung, (2002) Piezoresistive Cement-Based Materials for Strain Sensing. Journal of Intelligent Material Systems and Structures, 13(9), 599-609. https://doi.org/10.1106/104538902031861

[7] P.W. Chen, D.D.L. Chung (1993) Carbon fiber reinforced concrete for smart structures capable of non-destructive flaw detection, Smart Materials and Structures, Vol 2, Smart Materials and Structures DOI: https://doi.org/10.1088/0964-1726/2/1/004

[8] O. Galao, L. Bañón, F.J. Baeza, J. Carmona, P. Garcés, (2016) Highly Conductive Carbon Fiber Reinforced Concrete for Icing Prevention and Curing. Materials, Vol 9, 281, DOI: https://doi.org/10.3390/ma9040281

[9] S.Y. Lee, H.V. Le, D.J. Kim, (2019) Self-stress sensing smart concrete containing fine steel slag aggregates and steel fibers under high compressive stress, Construction and Building Materials, Volume 220, 149-160, https://doi.org/10.1016/j.conbuildmat.2019.05.197.

[10] W. Dong, W. Li, K. Wang, Z. Luo, D. Sheng, (2020) Self-sensing capabilities of cement-based sensor with layer-distributed conductive rubber fibres, Sensors and Actuators A: Physical, Vol 301, https://doi.org/10.1016/j.sna.2019.111763. 
[11] D. D. L. Chung, (2002). Piezoresistive Cement-Based Materials for Strain Sensing. Journal of Intelligent $\quad$ Material 599-609. https://doi.org/10.1106/104538902031861

[12] L.X. Zheng, X.H. Hui, Z.Q. Zhuo, (2005) Investigation on the Method of AC Measurement of Compression Sensibility of Carbon Fiber Cement Journal of Wuhan Urban Construction Institute. [13] S. Ding, Y. Ruan, X. Yu, B. Han, Y.Q. Ni, (2019) Self-monitoring of smart concrete column incorporatingCNT/NCB composite fillers modified cementitious sensors, Construction and Building Materials, Vol 201, 127-137, https://doi.org/10.1016/j.conbuildmat.2018.12.203.

[14] W. Dong, W. Li, K. Wang, B. Han, D. Sheng, S. P. Shah, (2020) Investigation on physicochemical and piezoresistive properties of smart MWCNT/cementitious composite exposed to elevated temperatures, Cement and Concrete Composites, Vol 112, https://doi.org/10.1016/j.cemconcomp.2020.103675.

[15] E. Teomete, O.I. Kocyigit, (2013) Tensile strain sensitivity of steel fiber reinforced cement matrix composites tested by split tensile test, Construction and Building Materials, Vol 47, 962968, https://doi.org/10.1016/j.conbuildmat.2013.05.095.

[16] B. Han, S. Ding, X. Yu, (2015) Intrinsic self-sensing concrete and structures: A review, Measurement, Vol 59, 110-128, https://doi.org/10.1016/j.measurement.2014.09.048.

[17] M. Chen, P. Gao, F. Geng, L. Zhang, H. Liu, (2017) Mechanical and smart properties of carbon fiber and graphite conductive concrete for internal damage monitoring of structure, Construction and Building Materials, Vol 142, 320-327, https://doi.org/10.1016/j.conbuildmat.2017.03.048.

[18] H. Siad, M. Lachemi, M. Sahmaran, H.A. Mesbah, K.A. Hossain, (2018) Advanced engineered cementitious composites with combined self-sensing and self-healing functionalities,

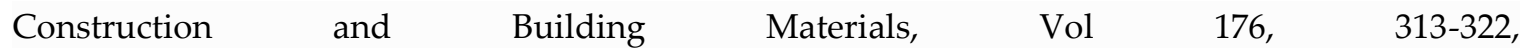
https://doi.org/10.1016/j.conbuildmat.2018.05.026. 
[19] E, Teomete, (2016) The effect of temperature and moisture on electrical resistance, strain sensitivity and crack sensitivity of steel fiber reinforced smart cement composite, Smart materials and structures, Vol 25, DOI: 10.1088/0964-1726/25/7/075024

[20] W. Dong, W. Li, Z. Tao, K. Wang, (2019) Piezoresistive properties of cement-based sensors: Review and perspective, Construction and Building Materials, Vol 203, Pages 146-163, https://doi.org/10.1016/j.conbuildmat.2019.01.081.

[21] A. Sassani, A Arabzadeh, H. Ceylan, S. Kim, S.M. Sajed Sadati, K. Gopalakrishnan, P.C. Taylor, H. Abdualla, (2018) Carbon fiber-based electrically conductive concrete for salt-free deicing of pavements, Journal of Cleaner Production, Volume 203, 799-809, https://doi.org/10.1016/j.jclepro.2018.08.315.

[22] J.M. Chiou, Q. Zheng, D.D.L. Chung, (1989) Electromagnetic interference shielding by carbon fibre reinforced cement, Composites, Vol 20, Issue 4, 379-381, https://doi.org/10.1016/00104361(89)90663-0.

[23] F. Yousuf, X. Wei, J. Zhou, (2020) Monitoring the setting and hardening behavior of cement paste by electrical resistivity measurement, Construction and Building Materials, Vol 252,118941, ISSN 0950-0618, https://doi.org/10.1016/j.conbuildmat.2020.118941.

[24] B.V. Derjaguin, (1987) Some results from 50 years' research on surface forces. In: Surface Forces and Surfactant Systems. Progress in Colloid \& Polymer Science, vol 74, DOI: https://doi.org/10.1007/BFb0109369

[25] C.F. Ferraris, F.H. Wittmann, (1987) Shrinkage mechanisms of hardened cement paste, Cement and Concrete Research, Vol 17, Issue 3, 453-464, https://doi.org/10.1016/00088846(87)90009-3.

[26] W. Hansen, (1987), Drying Shrinkage Mechanisms in Portland Cement Paste. Journal of the American Ceramic Society, Vol 70, Issue 5, 323-328. DOI: 10.1111/j.1151-2916.1987.tb05002.x 
[27] F. Rajabipour, J. Weiss, (2007) Electrical conductivity of drying cement paste. Materials and structures Vol 40, 1143-1160 DOI: https://doi.org/10.1617/s11527-006-9211-z

[28] G.E. Archie, (1942) The electrical resistivity log as an aid in determining some reservoir characteristics. Petroleum Transactions of AIME, Vol 146, 54-62, DOI: 10.2118/942054-g

[29] I. Balberg (1986) Excluded-volume explanation of Archie's law, Physical review. B, Vol 33,

Issue 5, 3618-3620, doi:10.1103/physrevb.33.3618.

[30] F. Rajabipour (2006) In situ electrical sensing andmaterial health monitoring of concrete structures,Ph.D.Dissertation,PurdueUniversity,WestLafayette, Indiana

[31] A. Revil, P.W.J. Glover (1997) Theory of ionic-surface electrical conduction in porous media. Physical Review B, Vol 55, Issue 3, 1757-1773 DOI:10.1103/PhysRevB.55.1757

[32] H. W. Whittington, J. McCarter, M. C. Forde (1981) The conduction of electricity through concrete, Magazine of Concrete Research, Vol 33:114, 48-60, https://www.icevirtuallibrary.com/doi/abs/10.1680/macr.1981.33.114.48

[33] E. J. Garboczi, (1990) Permeability, diffusivity, and microstructural parameters: A critical review, Cement and Concrete Research, Vol 20, Issue 4, 1990, 591-601, DOI: https://doi.org/10.1016/0008-8846(90)90101-3.

[34] R.B. Polder, (2001) Test methods for on-site measurement of resistivity of concrete - a RILEM TC-154 technical recommendation, Construction and Building Materials, Vol 15, Issues 23, 2001, 125-131, DOI: https://doi.org/10.1016/S0950 0618(00)00061-1.

[35] P. Xie, P. Gu, J.J. Beaudoin, (1996) Electrical percolation phenomena in cement composites containing conductive fibres. Journal of materials science, Vol 31,4093-4097. DOI: https://doi.org/10.1007/BF00352673 
[36] S. Wen, D.D.L. Chung, (2007) Double percolation in the electrical conduction in carbon fiber reinforced cement-based materials, Carbon, Vol 45, Issue 2, 263-267, https://doi.org/10.1016/j.carbon.2006.09.031.

[37] Y. Yang, (2002) Methods study on dispersion of fibers in CFRC, Cement and Concrete Research, Vol 32, Issue 5, 747-750, https://doi.org/10.1016/S0008-8846(01)00759-1.

[38] N. Banthia, S. Djeridane, M. Pigeon, (1992) Electrical resistivity of carbon and steel microfiber reinforced cements, Cement and Concrete Research, Vol 22, Issue 5, 804-814, DOI: https://doi.org/10.1016/0008-8846(92)90104-4.

[39] A. Belli, A. Mobili, T. Bellezze, F. Tittarelli, (2020) Commercial and recycled carbon/steel fibers for fiber-reinforced cement mortars with high electrical conductivity, Cement and Concrete Composites, Vol 109, 2020, 103569, ISSN 0958-9465, DOI: https://doi.org/10.1016/j.cemconcomp.2020.103569.

[40] L. Zhang, S. Ding, B. Han, X. Yu, Y.Q. Ni, (2019) Effect of water content on the piezoresistive property of smart cement-based materials with carbon nanotube/nanocarbon black composite filler, Composites Part A: Applied Science and Manufacturing, Vol 119, 8-20, https://doi.org/10.1016/j.compositesa.2019.01.010.

[41] W. Dong, W. Li, N. Lu, F. Qu, K. Vessalas, D. Sheng, (2019) Piezoresistive behaviours of cement-based sensor with carbon black subjected to various temperature and water content, Composites Part B: Engineering, Vol 178, https://doi.org/10.1016/j.compositesb.2019.107488. [42] NF EN 196-1 - September 2016

[43] S. Wen, D.D.L Chung, (2001) Electric polarization in carbon fiber-reinforced cement, Cement and Concrete Research, Vol 31, Issue 1, 141-147, https://doi.org/10.1016/S0008-8846(00)00382-3. 
[44] A. Berg, A G. A. Niklasson, A K. Brantervik, A B. Hedberg, A L. O. Nilsson, (1992) Dielectric properties of cement mortar as a function of water content, Journal of Applied Physics, 5897-5903, Vol 71, https://doi/abs/10.1063/1.350488

[45] B. Han, L. Zhang, C. Zhang, Y. Wang, X. Yu, J. Ou, (2016) Reinforcement effect and mechanism of carbon fibers to mechanical and electrically conductive properties of cement-based materials, Construction and Building Materials 125, Pages 479-489, https://doi. org/10.1016/j.conbuildmat.2016.08.063.

[46] J. Donnini, T. Bellezze, V. Corinaldesi, (2018) Mechanical, electrical and self-sensing properties of cementitious mortars containing short carbon fibers, J. Build. Eng. 20 8-14, https://doi.org/10.1016/j.jobe.2018.06.011.

[47] E. Demircilioğlu, E. Teomete, E. Schlangen, F. J. Baeza,(2019) Temperature and moisture effects on electrical resistance and strain sensitivity of smart concrete, (2019) Construction and Building Materials, Vol 224, Pages 420-427, https://doi.org/10.1016/j.conbuildmat.2019.07.091. [48] Ping Xie, Ping Gu, Zhongzi Xu, and J. J. Beaudoin., (1993) A rationalized a.c. impedence model for microstructural characterization of hydrating cement systems. Cement and Concrete Research, 23(2):359-367.

[49] J.M Torrents, T.O Mason, E.J Garboczi, (2000) Impedance spectra of fiber-reinforced cementbased composites: a modeling approach, Cement and Concrete Research, Vol 30, Issue 4, Pages 585-592, https://doi.org/10.1016/S0008-8846(00)00211-8. 